\title{
Organización retórica y relaciones de coherencia en el abstract de biología*
}

\author{
Rhetoric organization and coherence relations in the biology abstract

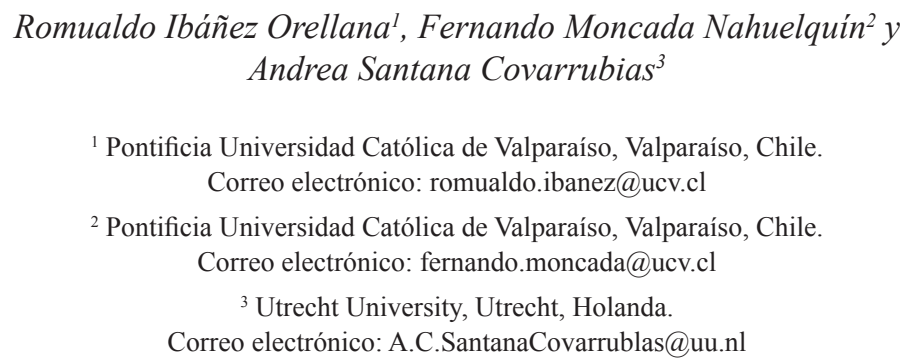

Debido a la importancia que el abstract ostenta en la comunicación científica, durante las últimas décadas numerosos especialistas se han dedicado a estudiarlo. Muchos de ellos han centrado su atención en la organización retórica de este género (Dos Santos 1996; Hyland 2000; Martín-Martín 2003; Lorés 2004), y sus resultados han demostrado sistemáticamente que dicha organización varía según la disciplina (Hyland 2000; Samraj 2002, 2005; Tseng 2011; Nasser 2013), lo que revela que cada disciplina ha convencionalizado sus propias formas de construir y transmitir su conocimiento. Desde este escenario, y entendiendo que los abstracts -como cualquier otro género académico- varían dependiendo de la disciplina, en el presente estudio describimos el abstract de la disciplina de biología en términos de su organización retórica y de la forma en que se establece la coherencia. Para dar cuenta de la organización retórica, utilizamos como marco de análisis inicial la propuesta de Hyland (2000), mientras que para las relaciones de coherencia utilizamos el marco de análisis propuesto por Ibáñez, Moncada y Santana (en prensa). El corpus de esta investigación está constituido por 80 abstracts en español, pertenecientes a artículos de investigación científica publicados en revistas especializadas. Nuestros datos revelan la escasa ocurrencia de movidas como 'propósito' y la alta frecuencia de otras como 'método', lo que ha permitido identificar las diferentes configuraciones retóricas mediante las cuales se organiza el abstract en esta disciplina. En cuanto a las relaciones de coherencia, no sólo hemos identificado las relaciones prototípicas de este género, sino que también aquellas que caracterizan cada movida.

Palabras clave: abstract, organización retórica, relaciones de coherencia, discurso académico 
Due to the importance that abstracts holds in scientific communication, during the last decades several specialists have studied it. Many of them have focused on the rhetorical organization of this genre (Dos Santos 1996; Hyland 2000; Martín-Martín 2003; Lorés 2004), and their results have systematically demonstrated that such organization varies among disciplines (Hyland 2000; Samraj 2002, 2005; Tseng 2011; Nasser 2013). The latter reveals that each discipline has fixed its own ways of building and transmitting knowledge. From this scenario, and understanding that abstract -as any other academic genre- vary depending on the discipline, the present research describes the abstract of biology in terms of its rhetoric organization and the way in which it establishes coherence. In order to account for rhetorical organization, we utilize the proposal of Hyland (2000) as a framework for initial analysis, while we use the analysis framework developed by Ibáñez, Moncada y Santana for coherence relations (in press). The research corpus is constituted by 80 abstracts in Spanish language, which belong to scientific research articles published by specialized journals. Our data show the scarce occurrence of moves as 'purpose' and the high frequency of others as 'method', which has enabled the identification of different rhetoric configurations through which abstracts are organized in this discipline. Regarding coherence relations, not only have we identified prototypical ones in this genre, but also those that characterize each move.

Key words: abstract, rhetoric organization, coherence relations, academic discourse

\section{INTRODUCCIÓN}

Sin lugar a dudas, el abstract cumple un rol central en diferentes actividades a través de las cuales se transmite el conocimiento científico. Por ejemplo, una de las formas de comunicación más importantes en contextos académicos se realiza a través de publicaciones en revistas científicas, las que, según Lorés (2004), están fuertemente determinadas por las características y por los argumentos presentados en el abstract. Otra de las actividades en las que este género juega un rol fundamental es en congresos y conferencias, ya que para participar en ellos, los investigadores deben enviar el abstract de sus colaboraciones a un comité de expertos, quienes aceptarán o rechazarán los trabajos atendiendo lo expuesto en él.

Debido a su relevancia, en los últimos treinta años, el abstract ha acaparado la atención de numerosos investigadores interesados en describir el discurso académico. Este interés ha resultado en una variedad de estudios, los que se han focalizado en diferentes rasgos de este género (para una revisión actualizada, ver Bondi y Lorés 2014). Así, existen trabajos que describen de manera pormenorizada su organización temática (Lorés 2004), otros han dado cuenta de su complejidad léxica (Gholami, Mosalli y Bidel 2012), existen aquellos que han descrito el léxico más frecuentemente utilizado (Farjami 2013) y los tiempos verbales prototípicos (Pezzine 2003), así como también el uso de voces pasivas y activas (Li 2011), sin dejar de lado aquellos que han indagado cómo el autor se posiciona en este género (Hyland y Tsé 2005; Lorés 2008; Pho 2008).

Si bien existe una gran cantidad y variedad de estudios focalizados en diversos rasgos del abstract, es indudable que uno de los aspectos más investigados de este género es su organización retórica (Salager-Meyer 1990, 1992; Dos Santos 1996; Martín-Martín 2003; Lores 2004) y la forma en que dicha organización se configura en diferentes disciplinas (Melander, Swales y Fredrickson 1997; Hyland 2000; 
Samraj 2002, 2005; Tseng 2011; Nasser 2013; Suntara y Usaha 2013; Saeeaw y Tangkriengsirisin 2014). Hasta ahora, los hallazgos obtenidos a partir de este tipo de estudios han permitido conocer las características globales del abstract. Sin embargo, poco se sabe acerca de la relación entre tales características globales y otro tipo de rasgos de carácter local. Un trabajo interesante en esta línea es el realizado por Lorés (2014), en el cual compara la organización retórica y las características léxico-gramaticales de abstracts en inglés y en español de artículos de investigación científica pertenecientes a la disciplina de sociología.

Otro rasgo de carácter local que permite complementar las descripciones de la organización retórica del abstract son las relaciones de coherencia. Dichas relaciones y la forma en que se manifiestan constituyen un aspecto central sobre el cual se han desarrollado numerosos y variados planteamientos en las últimas décadas (van Dijk 1977; Mann y Thompson 1988; Redeker 2000; Spooren y Sanders 2001; Renkema 2009; Taboada 2009), pues permiten dar cuenta no sólo de la forma en que se articula el sentido de un texto, sino que también de la forma en que el discurso varía dependiendo de los contextos en que se utiliza (Ibáñez, Moncada y Santana en prensa).

Por lo anteriormente expuesto, y adhiriendo al principio de variación lingüística impuesta por el contexto disciplinar (Bhatia 2004; Hyland 2004), en este trabajo nos proponemos describir el abstract de la disciplina de biología desde dos perspectivas complementarias. En concreto, pretendemos describir este género en términos de su organización retórica y, también, a partir de las relaciones de coherencia que lo articulan. Para alcanzar nuestro objetivo, la organización retórica es descrita usando como marco inicial la propuesta de Hyland (2000). A su vez, las relaciones de coherencia son identificadas a partir del marco propuesto por Ibáñez, Moncada y Santana (en prensa). El corpus de trabajo está constituido por 80 abstracts escritos en español, extraídos de artículos de investigación publicados en revistas especializadas del área de biología.

En el primer apartado, presentamos los fundamentos teóricos en los cuales se basa nuestra investigación. Luego, describimos la metodología que utilizamos para llevar a cabo el análisis. Finalmente, presentamos y comentamos los resultados obtenidos.

\section{FundAMENTACIÓN TEÓRICA}

\subsection{El abstract como género del discurso académico}

El discurso académico es considerado como una vía fundamental para la construcción y la transmisión del conocimiento en las disciplinas (Bathia 2004; Hyland 2004; Silver 2006). Se constituye como un discurso que refleja las prácticas sociales que ocurren al interior de cada comunidad disciplinar, y manifiesta la forma de pensar de éstas, revelando, de este modo, las diferentes maneras en que tales comunidades diseminan sus ideas y construyen sus saberes (Hyland 2009, 2011). De ahí que sea posible sostener que en la medida en que los nuevos miembros de una comunidad interactúan exitosamente con los textos que conforman el discurso académico de su disciplina, no sólo adquieren conocimiento especializado, sino que también se integran a su comunidad disciplinar de referencia (Swales 1990; Bhatia 2002; Hyland 2004; Hyland y Bondi 2006). 
Entre los estudios que han abordado el discurso académico se destacan aquellos que han descrito sus rasgos léxico-gramaticales a partir de diferentes registros (Biber, Conrad y Reppen 1998; Biber et al. 1999) y en distintas disciplinas (Varantola 1984; Halliday 1988). También existen aquellos que han caracterizado diferentes mecanismos discursivos, tales como los atenuadores retóricos (Salager-Meyer 1994; Hyland 1996) o los elementos que dan cuenta del posicionamiento del hablante (Grabe y Kaplan 1997; Charles 2003; Bolívar, Beke y Shiro 2010). Asimismo, se destacan investigaciones que han explorado la organización retórica de diferentes géneros académicos (Bazerman 1988; Swales 1990; Bunton 2002; Pezzini 2003; Bathia 2004; Hyland 2008; Ibáñez 2008, 2010; Samraj 2008). Tales trabajos han demostrado que los géneros académicos varían a través de las disciplinas, lo que se atribuye, como ya hemos venido señalando, a que cada una de ellas tiene sus propias convenciones y determina la formulación y la negociación del conocimiento especializado.

Entre los diversos géneros constitutivos del discurso académico, uno que ha concitado especial interés por parte de investigadores de diversas partes del mundo es el abstract. Gran parte de las discusiones en torno a este género ha estado focalizada en torno a dos aspectos: su estatus como género discursivo (Nasser 2013) y su propósito comunicativo (Dos Santos 1996). Así, por ejemplo, Bhatia (1993) sostiene que el propósito del abstract es entregar al lector información exacta y precisa acerca del contenido del artículo al que precede, mientras que, para Ventola (1997), el abstract corresponde a una sección que proporciona lo medular del artículo de la manera más eficiente posible. Sin embargo, autores como Hyland (2000) sostienen que el abstract no es solamente una versión resumida del artículo, sino que tiene un objetivo aún más importante en la actividad académica y científica: persuadir al lector de que vale la pena leer tal artículo, lo que le daría al abstract el carácter de género en sí mismo. De acuerdo a lo anterior, el abstract debiera ser lo suficientemente eficaz para permitir a los investigadores cumplir su objetivo de ser publicados o aceptados en un congreso.

\subsection{Las movidas retóricas como una herramienta para describir el abstract}

Con el propósito de mejorar las prácticas discursivas asociadas a la producción de abstracts, durante las últimas décadas se han desarrollado numerosos estudios orientados a caracterizarlo. Para ello, el aspecto que más se ha indagado es su organización retórica. Quienes se interesan en este tipo de estudios (Samraj 2002; Kanoksilaphatam 2005; Nasser 2013), sostienen que el abstract está constituido por movidas, las que corresponden a unidades discursivas o retóricas que cumplen un propósito comunicativo en el discurso. Entre los estudios de este tipo es posible identificar dos propuestas que han sido desarrolladas exclusivamente para este género. Una de ellas es la propuesta elaborada por Dos Santos (1996), para quien el abstract se constituye retóricamente a partir de cinco movidas: 1) situar la investigación, 2) presentar la investigación, 3) describir la metodología, 4) resumir los resultados, y 5) discutir la investigación. La otra propuesta es la aportada por Hyland (2000), quien también sostiene que el abstract se organiza mediante cinco movidas: 1) introducción, 2) propósito, 3) método, 4) producto, y 5) conclusión. En la Tabla 1 presentamos las movidas propuestas por ambos autores, junto a su propósito comunicativo: 
Tabla 1: Organización retórica del abstract

\begin{tabular}{|l|l|l|l|}
\hline \multicolumn{2}{|c|}{ Dos Santos (1996) } & \multicolumn{2}{c|}{ Hyland (2000) } \\
\hline Movida & Propósito comunicativo & Movida & Propósito comunicativo \\
\hline $\begin{array}{l}\text { Situar la } \\
\text { investigación }\end{array}$ & $\begin{array}{l}\text { Proporcionar al lector } \\
\text { orientación acerca del área } \\
\text { de donde proviene el autor } \\
\text { y lo motiva a examinar el } \\
\text { trabajo. }\end{array}$ & Introducción & $\begin{array}{l}\text { Establecer el contexto } \\
\text { del trabajo y motivar la } \\
\text { investigación. }\end{array}$ \\
\hline $\begin{array}{l}\text { Presentar la } \\
\text { investigación }\end{array}$ & $\begin{array}{l}\text { Describir las } \\
\text { características centrales } \\
\text { del trabajo o presentar su } \\
\text { propósito. }\end{array}$ & Propósito & $\begin{array}{l}\text { Indicar el propósito, tesis } \\
\text { o hipótesis. Señalar la } \\
\text { intención que motiva el } \\
\text { trabajo. }\end{array}$ \\
\hline $\begin{array}{l}\text { Describir la } \\
\text { metodología }\end{array}$ & $\begin{array}{l}\text { Indicar el diseño del } \\
\text { estudio en términos de } \\
\text { sujetos, procedimientos, } \\
\text { materiales, variables, } \\
\text { según el tipo de } \\
\text { experimentación. }\end{array}$ & Método & $\begin{array}{l}\text { Proporcionar información } \\
\text { sobre diseño, } \\
\text { procedimientos, enfoque, } \\
\text { etc. }\end{array}$ \\
\hline $\begin{array}{l}\text { Resumir los } \\
\text { resultados }\end{array}$ & $\begin{array}{l}\text { Resumir brevemente los } \\
\text { hallazgos principales de } \\
\text { la investigación e indicar } \\
\text { cómo se manipularon los } \\
\text { datos. }\end{array}$ & Producto & $\begin{array}{l}\text { Presentar los hallazgos o } \\
\text { resultados principales o qué } \\
\text { se logró. }\end{array}$ \\
\hline $\begin{array}{l}\text { Realizar afirmaciones } \\
\text { en base a los hallazgos } \\
\text { reportados. }\end{array}$ & Conclusión & $\begin{array}{l}\text { Interpretar los resultados } \\
\text { más allá del alcance del } \\
\text { trabajo, generar inferencias, } \\
\text { apuntar hacia posibles } \\
\text { aplicaciones. }\end{array}$ \\
\hline
\end{tabular}

Como se puede observar, ambas propuestas son similares, tanto en la cantidad de movidas que presentan como en los propósitos que éstas cumplen. Junto con esta similitud, también cabe insistir en que ambas propuestas, basadas en el modelo CARS (Swales 1990), han sido desarrolladas para describir exclusivamente la organización retórica de este género. Además, ambas propuestas emergen a partir de estudios de corpus. Así, mientras Dos Santos (1996) analizó 94 abstracts de lingüística aplicada, Hyland (2000) analizó 800 abstracts de cinco disciplinas, lo que ha permitido obtener caracterizaciones exhaustivas de este género.

A pesar de que existe consenso acerca de que el abstract se configura retóricamente a través de estas movidas, un aspecto central que se ha corroborado sistemáticamente en numerosas investigaciones es que esta organización varía según la disciplina. Así, por ejemplo, Pho (2008), siguiendo el modelo de Dos Santos (1996), identificó que las movidas 'presentar la investigación', 'resumir los resultados' y 'describir la metodología' son obligatorias en lingüística aplicada y en tecnología educacional, mientras que las movidas 'situar la investigación' y 'discutir los resultados' son opcionales en ambas disciplinas, dada su baja frecuencia. Asimismo, Ge y Yang (2005) 
identificaron que los abstracts en las disciplinas de ingeniería electrónica, cirugía y finanzas presentan las mismas movidas, pero que su frecuencia es significativamente diferente. Por ejemplo, en cirugía, la movida 'método' se identificó en prácticamente la totalidad de los abstracts, mientras que en finanzas esta movida fue identificada en escasos abstracts.

\subsection{Las relaciones de coherencia como una herramienta para describir el abstract}

Si bien no cabe duda del rol central que las relaciones de coherencia han tenido en los estudios del discurso durante los últimos cuarenta años, tampoco se puede negar la controversia respecto de la forma en que han sido concebidas por quienes las han estudiado. Así, mientras que unos les han atribuido una naturaleza textual, o bien, puramente lingüística (Halliday y Hasan 1976), otros las han considerado como un fenómeno cognitivo (van Dijk 1980; Sanders y Spooren 2001; Renkema 2009). Tal controversia surge pues las relaciones de coherencia se establecen a partir de la vinculación de dos o más unidades de sentido, y estas unidades han sido concebidas de diversas maneras según la perspectiva teórica y metodológica con la cual se ha abordado el fenómeno. Así, se les ha denominado como cláusulas o complejos clausulares (Halliday y Hasan 1976; Martin 1992; Matthiesen 2002), oraciones (van Dijk 1980; Albadalejo 1981; De Beaugrande y Dressler 1981; Bernárdez 1982), fragmentos del texto (Mann y Thompson 1988; Taboada y Mann 2006), proposiciones (Kintsch 1974, 1988), segmentos discursivos (Sanders, Spooren y Noordman 1992, 1993; Spooren y Sanders 2008), y eventos (Zwaan y Radvansky 1998; Ibáñez, Moncada y Santana en prensa).

En el presente trabajo, al abordar las relaciones de coherencia, adherimos a la perspectiva cognitiva planteada por Ibáñez, Moncada y Santana (en prensa), que surge como un trabajo complementario a los estudios previos de coherencia (Sweetser 1990; Sanders, Spooren y Noordman 1992, 1993; Spooren y Sanders 2008; Renkema 2009). Es así que entendemos la coherencia como una representación mental que surge y se desarrolla a partir del establecimiento de relaciones de sentido sustentadas en la información textual. Estas relaciones se establecen a partir de la vinculación de eventos (E), los que en su forma básica están constituidos por dos entidades: al menos un concepto (C), que puede ser una persona, actividad, objeto, etc., y una acción (A), que puede ser un proceso o estado. Por lo tanto, en el caso de "María corre", María es $\mathrm{C}$, correr es A, y ambos constituyen un E. Tales eventos pueden ser de carácter ideacional, porque dan cuenta de hechos del mundo, tal como se observa en el caso anterior. También pueden ser de carácter inferencial, dado que se constituyen por las representaciones de los estados mentales de los participantes y/o hablantes, tal como se observa en el ejemplo 1). O bien, pueden ser de carácter ilocutivo, ya que manifiestan actos de este tipo, tal como se aprecia en el ejemplo 2).

1) María corre $\left(\mathrm{E}_{1}\right)$. Es probable que ella sea una mujer atlética $\left(\mathrm{E}_{2}\right)$.

$\mathrm{E}_{2}$ corresponde a una deducción o inferencia generada por el hablante como consecuencia del hecho $\mathrm{E}_{1}$.

2) Hace frio $\left(\mathrm{E}_{1}\right)$ ¿Por qué no enciendes la calefacción? $\left(\mathrm{E}_{2}\right)$. 
$\mathrm{E}_{2}$ corresponde a un acto ilocutivo realizado por el participante del discurso, motivado por el hecho $\mathrm{E}_{1}$.

En este estudio describimos el abstract en términos de las relaciones que articulan su coherencia relacional y aditiva. La coherencia relacional se establece a partir de la vinculación de eventos dada la proximidad temática que existe entre ellos, mientras que la aditiva lo hace a partir de la vinculación de eventos debido a la complementariedad informativa entre éstos o sus partes constituyentes (concepto y acción). Para el análisis de estos tipos de coherencia, la propuesta en la que nos basamos propone una serie de criterios e indicadores, los que se describen a continuación.

\subsubsection{Criterios de análisis para la coherencia relacional}

\subsubsection{Operación básica}

Este criterio permite distinguir el tipo de relación según el grado de proximidad temática entre los eventos vinculados. Si los eventos comparten un tópico, hablamos de relaciones de adyacencia y si, aparte de eso, un evento implica el otro, hablamos de relaciones de causalidad. Los ejemplos 3a) y 3b) dan cuenta de cada relación.

3a) María corre $\left(E_{1}\right)$. Pedro prefiere nadar $\left(E_{2}\right)$.

En este caso sólo existe proximidad temática dado que comparten un tema: preferencias deportivas. Por lo tanto, se genera una relación de adyacencia.

3b) María corre $\left(\mathrm{E}_{1}\right)$. Su doctor le recomendó hacer ejercicios $\left(\mathrm{E}_{2}\right)$.

Aquí, además de proximidad temática existe implicancia, pues el tema compartido es el deporte y la implicancia radica en que $\mathrm{E}_{2}$ es el motivo para $\mathrm{E}_{1}$. Por lo tanto, se genera una relación de causalidad en la cual $\mathrm{E}_{1}$ cumple la función de consecuente (Q), y $\mathrm{E}_{2}$, la de antecedente (P).

\subsubsection{Fuente de coherencia}

Este criterio permite distinguir el tipo de relación según la naturaleza del evento que cumple la función Q. Si la naturaleza del evento Q es ideacional, nos referimos a una relación de contenido; si es inferencial, corresponde a una relación epistémica; y si es ilocutiva, hablamos de una relación de acto de habla. Además, a partir del indicador de contenido surgen otros tres subindicadores: volitivo, deóntico y neutral. El subindicador volitivo permite describir relaciones de causalidad mediadas por la voluntad. El subindicador deóntico permite describir relaciones que están mediadas por la obligación. Por último, el subindicador neutral permite describir las relaciones que no están mediadas ni por la voluntad ni por la obligación.

A continuación, presentamos los ejemplos 4), 5) y 6) que dan cuenta de cada uno de estos tipos de relación. 
4a.1) (Q) María corre cada semana porque (P) quiere tener un buen estado físico.

Q es de naturaleza ideacional, es decir, corresponde a un hecho del mundo. Además, Q está mediado por la voluntad o intención. Por lo tanto, existe una relación de contenido volitiva.

4a.2) (P) Si el sujeto no hace entrega de los documentos solicitados en el plazo establecido, (Q) debe pagar una multa.

Q es de naturaleza ideacional y existe una obligación impuesta. Por lo tanto, se establece una relación de contenido deóntico.

4a.3) (P) Hubo un temblor fuerte. (Q) El cuadro se cayó del muro.

Q es de naturaleza ideacional, es decir, corresponde a un hecho del mundo. En este caso, observamos que Q no está mediado por la intención ni la voluntad. Por lo tanto, se genera una relación de contenido neutral.

4a.4) María corre. Pedro prefiere nadar.

En esta relación notamos que ninguno de los eventos cumple la función de Q, es decir, no existe implicancia. Además, ambos eventos corresponden a hechos del mundo. Entonces, corresponde a una relación de adyacencia en la cual sólo existe proximidad temática $\mathrm{y}$, por lo tanto, únicamente puede generarse una relación de contenido neutral.

5a) (P) María corre. (Q) Es probable que ella sea una mujer atlética.

Q es de naturaleza inferencial, ya que corresponde a una deducción motivada por la evidencia (P). Por ello, la relación es epistémica.

6a) (P) Hace frío. (Q) ¿Por qué no enciendes la calefacción?

Q es de naturaleza ilocutiva, es decir, corresponde a una sugerencia u orden. Por lo tanto, la relación es de acto de habla.

\subsubsection{Orden de los eventos}

Este criterio es aplicable sólo a las relaciones de causalidad, y permite identificar la disposición del antecedente (P) y el consecuente (Q) en la relación entre los eventos. Si el primer evento corresponde al antecedente como en el caso de 4a.3), el orden de la relación es básico. $\mathrm{Si}$, por el contrario, el primer evento corresponde al consecuente como en el caso de 4a.1), el orden es no básico.

\subsubsection{Polaridad}

Este criterio permite distinguir el tipo de relación positiva o negativa entre los eventos según el cumplimiento de expectativas. Si Q corresponde a la expectativa 
generada por P, la relación es positiva. Por el contrario, si Q no corresponde a la expectativa, la relación es negativa. En el ejemplo 7a) y 7b) se presenta una relación con polaridad positiva y negativa, respectivamente.

7a) (P) Hoy es un día festivo. (Q) Todos los mercados y tiendas están cerrados.

7b) (P) La mayoría de las personas trabaja de lunes a viernes. (Q) Sin embargo, Pedro tuvo que trabajar el domingo.

\subsubsection{Criterios de análisis para la coherencia aditiva}

\subsubsection{Foco de información}

Este criterio permite distinguir cuál es el elemento que está siendo complementado con información adicional en una relación entre eventos. Puede complementarse información en relación a un evento en su totalidad (E), a un concepto $(\mathrm{C})$, o a una acción (A) constituyente de otro evento. En los ejemplos 8a), 8b) y 8c) se da cuenta de cada una de estas formas de complementar información.

8a) $\left(\mathrm{E}_{1}\right)$ Pedro realizó horas extras en su trabajo. $\left(\mathrm{E}_{2}\right)$ Tal situación era muy típica entre los más jóvenes del departamento de ventas.

$\mathrm{E}_{2}$ complementa información a $\mathrm{E}_{1}$ en su totalidad.

8b) $\left(\mathrm{E}_{1}\right)$ Pedro tuvo una lesión en su pie. $\left(\mathrm{E}_{2}\right)$ Está fracturado y presenta varios hematomas.

$\mathrm{E}_{2}$ complementa al concepto "pie" presente en $\mathrm{E}_{1}$.

8c) $\left(\mathrm{E}_{1}\right)$ Pedro visitó a María. $\left(\mathrm{E}_{2}\right)$ Fue la semana pasada, durante la tarde del jueves.

$\mathrm{E}_{2}$ complementa información a la acción "visitar" presente en $\mathrm{E}_{1}$.

\subsubsection{Tipo de información}

Este criterio permite identificar la naturaleza de la información que complementa. Si el evento que complementa da cuenta de características del evento anterior o de un concepto constituyente de un evento anterior, como en el caso de 8 (a) y 8(b), respectivamente, hablamos de información adjetival; si da cuenta de antecedentes acerca de cómo, cuándo y dónde ocurre la acción de un evento anterior, corresponde a información adverbial; $y$, por último, si el evento complementa el evento anterior, haciendo referencia a la estructura o al contenido del texto, nos referimos a información meta discursiva. En los ejemplos 9a.1), 9a.2), 9a.3) presentamos la información complementaria adverbial, y en 10) la información complementaria meta discursiva.

9a.1) $\left(\mathrm{E}_{1}\right)$ Pedro expuso una maqueta para el nuevo proyecto. $\left(\mathrm{E}_{2}\right)$ Tardó 30 minutos.

$\mathrm{E}_{2}$ complementa información acerca de cuánto tardó la acción de $\mathrm{E}_{1}$. 
9a.2) $\left(E_{1}\right)$ Pedro expuso una maqueta para el nuevo proyecto. $\left(E_{2}\right)$ Realizó su presentación el viernes pasado.

$\mathrm{E}_{2}$ complementa información acerca de cuándo ocurre la acción de $\mathrm{E}_{1}$.

9a.3) $\left(E_{1}\right)$ Pedro expuso una maqueta para el nuevo proyecto. $\left(E_{2}\right)$ Lo hizo en la galería del Museo de Arte Contemporáneo.

$\mathrm{E}_{2}$ complementa información acerca de dónde ocurre la acción de $\mathrm{E}_{1}$.

10) $\left(E_{1}\right)$ Existen diversas opiniones respecto de la inseminación in vitro. $\left(E_{2}\right)$ En el capítulo 1 y 2 se hace un recorrido por tales perspectivas.

$\mathrm{E}_{2}$ complementa información aludiendo a la estructura del texto y complementa a $\mathrm{E}_{1}$ en su totalidad.

Los diferentes tipos de relaciones de coherencia relacional y aditiva emergen a partir de la combinación de los criterios e indicadores anteriormente descritos. Para revisar en detalle cada una de las relaciones de coherencia, sus descripciones y un ejemplo, presentamos las siguientes tablas:

Tabla 2: Descripción de las relaciones de adyacencia

\begin{tabular}{|c|l|l|l|}
\hline Nombre & \multicolumn{1}{|c|}{ Definición } & Formalización & \multicolumn{1}{c|}{ Ejemplo } \\
\hline Conjunción & $\begin{array}{l}\text { Relación que se } \\
\text { establece cuando } \\
\text { dos eventos se } \\
\text { vinculan a partir } \\
\text { de una situación } \\
\text { contextual común. }\end{array}$ & $\begin{array}{l}\text { En este trabajo intentaremos poner de } \\
\text { relieve algunas cuestiones relativas } \\
\text { a la discriminación por vejez y nos } \\
\text { detendremos en la situación de los } \\
\text { ancianos institucionalizados. }\end{array}$ \\
\hline Oposición & $\begin{array}{l}\text { Relación que se } \\
\text { establece cuando } \\
\text { un evento se } \\
\text { contrapone a otro. }\end{array}$ & P pero Q & $\begin{array}{l}\text { Algunas de esas reacciones tuvieron } \\
\text { una influencia positiva, fueron útiles, } \\
\text { coadyuvaron a hacer más estable el } \\
\text { sistema en cuestión y a alargar su } \\
\text { existencia. Por el contrario, otras fueron } \\
\text { perjudiciales, observaron un carácter } \\
\text { negativo y condujeron a la destrucción. }\end{array}$ \\
\hline Sustitución & $\begin{array}{l}\text { Relación que se } \\
\text { establece cuando } \\
\text { un evento excluye } \\
\text { a otro. }\end{array}$ & $\begin{array}{l}\text { P en vez de Q hidrocarburos de los meteoritos no } \\
\text { se conformaron, originariamente, sino } \\
\text { que eran productos de la desintegración } \\
\text { de organismos que vivieron en otros } \\
\text { tiempos en esos cuerpos celestes. }\end{array}$ \\
\hline Disyunción & $\begin{array}{l}\text { Relación que se } \\
\text { establece cuando } \\
\text { un evento es } \\
\text { alternativo a otro. }\end{array}$ & $\begin{array}{l}\text { P o Q posible que los hidrocarburos de los } \\
\text { meteoritos hayan desaparecido o que, } \\
\text { simplemente, jamás hayan existido. }\end{array}$ \\
\hline
\end{tabular}




\begin{tabular}{|l|l|l|l|}
\hline Secuencia & $\begin{array}{l}\text { Relación que } \\
\text { se luego Q } \\
\text { entre establece } \\
\text { consecutivos a } \\
\text { partir del orden en } \\
\text { que suceden. }\end{array}$ & $\begin{array}{l}\text { Entonces, éste se sitúa en una posición } \\
\text { excéntrica, y las pocas células que } \\
\text { quedan rodeando el ovocito forman } \\
\text { el disco prolígero. Luego aparece el } \\
\text { folículo terciario o folículo de Graaf, } \\
\text { que se caracteriza por la proliferación } \\
\text { de dos capas de tejido conjuntivo bien } \\
\text { diferenciadas en la zona más externa de } \\
\text { la capa granulosa. }\end{array}$ \\
\hline
\end{tabular}

Tabla 3: Descripción de las relaciones causales

\begin{tabular}{|c|c|c|c|}
\hline Nombre & Definición & Formalización & Ejemplo \\
\hline $\begin{array}{l}\text { Causa- } \\
\text { efecto }\end{array}$ & $\begin{array}{l}\text { Relación que se } \\
\text { establece cuando uno } \\
\text { o más eventos causan } \\
\text { otro(s). }\end{array}$ & P causa Q & $\begin{array}{l}\text { De vez en cuando aparecen microbios } \\
\text { mutantes que son resistentes al } \\
\text { antibiótico y transmiten a su progenie } \\
\text { el gen o los genes de su resistencia. } \\
\text { El resultado es que los mutantes } \\
\text { resistentes proliferan, mientras que los } \\
\text { microbios susceptibles se extinguen. }\end{array}$ \\
\hline $\begin{array}{l}\text { Efecto- } \\
\text { causa }\end{array}$ & $\begin{array}{l}\text { Relación que se } \\
\text { establece cuando uno } \\
\text { o más eventos han sido } \\
\text { causados por otro(s). }\end{array}$ & $\begin{array}{l}Q \text { es causado } \\
\text { por } P\end{array}$ & $\begin{array}{l}\text { Después de una comida, es común } \\
\text { oír que el estómago hace ruido. La } \\
\text { causa es una de las diversas fases de } \\
\text { indigestión. }\end{array}$ \\
\hline $\begin{array}{l}\text { Contraste } \\
\text { básico }\end{array}$ & $\begin{array}{lr}\text { Relación } \quad \text { que } & \text { se } \\
\text { establece } & \text { cuando uno } \\
\text { o más } & \text { eventos causan } \\
\text { otro(s), r distinto(s) } \\
\text { al(los)r usualmente } \\
\text { esperado(s). }\end{array}$ & Aunque P, Q & $\begin{array}{l}\text { En el Cono Sur de América del } \\
\text { Sur existen } 15 \text { especies que se } \\
\text { distribuyen en una amplia variedad de } \\
\text { ambientes, en estrecha relación con } \\
\text { las actividades humanas (Redford } \\
\& \text { Eisenberg 1992; Cuéllar 2008). } \\
\text { Sin embargo, hasta la actualidad } \\
\text { se ha generado escasa información } \\
\text { metódica sobre aspectos básicos de } \\
\text { su biología. }\end{array}$ \\
\hline $\begin{array}{l}\text { Contraste } \\
\text { no básico }\end{array}$ & $\begin{array}{l}\text { Relación que se } \\
\text { establece cuando uno o } \\
\text { más eventos, distintos } \\
\text { a los usualmente } \\
\text { esperados, han sido } \\
\text { causados por otros. }\end{array}$ & Q a pesar de $P$ & $\begin{array}{l}\text { Las poblaciones de bacalao del este } \\
\text { de Canadá, alguna vez abundantes, } \\
\text { actualmente casi se han extinguido, a } \\
\text { pesar de que hace más de una década } \\
\text { se impusieron severas restricciones a } \\
\text { la pesca. }\end{array}$ \\
\hline $\begin{array}{l}\text { Condición- } \\
\text { evento }\end{array}$ & $\begin{array}{lr}\text { Relación } & \text { que re } \\
\text { establece } & \text { cuando } \\
\text { uno o más } & \text { eventos o } \\
\text { estados } & \text { determinan } \\
\text { la (no) } & \text { ocurrencia de } \\
\text { otros. } & \end{array}$ & Si P, Q & $\begin{array}{l}\text { Si el demandado se encuentra en un } \\
\text { territorio jurisdiccional diverso o } \\
\text { fuera del territorio de la República, } \\
\text { el término para contestar la demanda } \\
\text { será de dieciocho días. }\end{array}$ \\
\hline
\end{tabular}




\begin{tabular}{|c|c|c|c|}
\hline $\begin{array}{l}\text { Evento- } \\
\text { condición }\end{array}$ & $\begin{array}{llr}\text { Relación } & \text { que } & \text { se } \\
\text { establece } & \text { cuando } & \text { la } \\
\text { (no) ocurrencia } & \text { de } \\
\text { cierto(s) } & \text { evento(s) } \\
\text { depende } & \text { de } & \text { la } \\
\text { ocurrencia de otro(s). }\end{array}$ & Q si $P$ & $\begin{array}{l}\text { El término de emplazamiento para } \\
\text { contestar la demanda será de quince } \\
\text { días si el demandado es notificado } \\
\text { en la comuna donde funciona el } \\
\text { tribunal. }\end{array}$ \\
\hline $\begin{array}{l}\text { Razón- } \\
\text { acción }\end{array}$ & 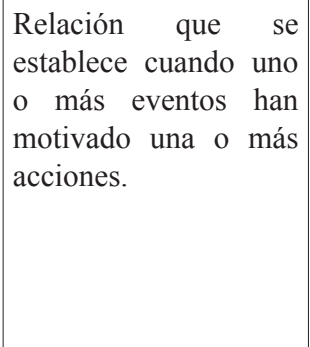 & $\begin{array}{l}\text { P ha motivado } \\
\text { la acción } Q\end{array}$ & $\begin{array}{l}\text { No existen estudios taxonómicos y } \\
\text { ecológicos sobre los invertebrados } \\
\text { fluviales del suroeste de la Patagonia, } \\
\text { tal como ocurre en la cuenca del } \\
\text { río Baker. Dado este marco, el } \\
\text { presente estudio propone analizar } \\
\text { la distribución espacial de los } \\
\text { macroinvertebrados bentónicos de la } \\
\text { cuenca del río Baker. }\end{array}$ \\
\hline $\begin{array}{l}\text { Acción- } \\
\text { razón }\end{array}$ & $\begin{array}{l}\text { Relación que se } \\
\text { establece cuando una o } \\
\text { más acciones han sido } \\
\text { motivadas por uno o } \\
\text { más eventos. }\end{array}$ & $\begin{array}{l}\text { La acción Q es } \\
\text { motivada por P }\end{array}$ & $\begin{array}{l}\text { No trataremos este aspecto de } \\
\text { la cuestión, ya que no queda } \\
\text { comprendido dentro del plan de estos } \\
\text { apuntes. }\end{array}$ \\
\hline $\begin{array}{l}\text { Propósito- } \\
\text { acto }\end{array}$ & $\begin{array}{l}\text { Relación que se } \\
\text { establece cuando, para } \\
\text { el logro de uno o más } \\
\text { objetivos, se llevan } \\
\text { a cabo una o más } \\
\text { acciones. }\end{array}$ & $\begin{array}{ll}\text { Para P } & \text { se } \\
\text { realiza Q } & \\
& \end{array}$ & $\begin{array}{l}\text { El legislador con el fin de superar } \\
\text { los inconvenientes que causaba } \\
\text { el determinar cuáles eran los } \\
\text { instrumentos fundantes y el plazo } \\
\text { que existía para impugnar los } \\
\text { documentos que se acompañaban a } \\
\text { la demanda, modificó el artículo } 255 .\end{array}$ \\
\hline $\begin{array}{l}\text { Acto- } \\
\text { propósito }\end{array}$ & $\begin{array}{llr}\text { Relación } & \text { que } & \text { se } \\
\text { establece } & \text { cuando } & \text { se } \\
\text { llevan a cabo una o más } \\
\text { acciones } & \text { para lograr } \\
\text { uno o más objetivos. }\end{array}$ & $\begin{array}{l}\text { Se realiza Q } \\
\text { para } \mathrm{P}\end{array}$ & $\begin{array}{l}\text { El presente trabajo seguirá el mismo } \\
\text { plan, salvo ligeras modificaciones, } \\
\text { para un mejor orden metodológico } \\
\text { de la exposición. }\end{array}$ \\
\hline $\begin{array}{l}\text { Condición- } \\
\text { obligación }\end{array}$ & $\begin{array}{l}\text { Relación que se } \\
\text { establece cuando la } \\
\text { (no) ocurrencia de uno } \\
\text { o más eventos impone } \\
\text { la ejecución de una o } \\
\text { más acciones. }\end{array}$ & $\begin{array}{l}\text { Si P se debe } \\
\text { realizar Q }\end{array}$ & $\begin{array}{l}\text { Si se rechaza la conciliación o no se } \\
\text { verifica el comparendo, el secretario } \\
\text { deberá certificar este hecho, y la } \\
\text { causa seguirá su curso. }\end{array}$ \\
\hline $\begin{array}{l}\text { Obligación- } \\
\text { condición }\end{array}$ & $\begin{array}{l}\text { Relación que se } \\
\text { establece cuando la } \\
\text { ejecución de una o más } \\
\text { acciones es impuesta } \\
\text { por la (no) ocurrencia } \\
\text { de uno o más eventos. }\end{array}$ & $\begin{array}{l}\text { Se debe realizar } \\
\text { Q si P }\end{array}$ & $\begin{array}{l}\text { También lo debe hacer si no han } \\
\text { concurrido todas las partes. }\end{array}$ \\
\hline
\end{tabular}




\begin{tabular}{|c|c|c|c|}
\hline $\begin{array}{l}\text { Argumento- } \\
\text { afirmación }\end{array}$ & $\begin{array}{l}\text { Relación que se } \\
\text { establece cuando se } \\
\text { utiliza un evento como } \\
\text { prueba para sustentar } \\
\text { una afirmación. }\end{array}$ & P respalda Q & $\begin{array}{l}\text { Los documentos suministran } \\
\text { una representación permanente y } \\
\text { relativamente segura de los hechos } \\
\text { que pueden interesar más tarde a } \\
\text { un proceso o que suelen hacerse } \\
\text { valer en las relaciones de sociedad } \\
\text { extraprocesalmente, por lo cual } \\
\text { es enorme su importancia como } \\
\text { instrumento de certeza jurídica, de } \\
\text { realización espontánea y pacífica de } \\
\text { los derechos. }\end{array}$ \\
\hline $\begin{array}{l}\text { Afirmación- } \\
\text { argumento }\end{array}$ & $\begin{array}{l}\text { Relación que se } \\
\text { establece cuando una } \\
\text { afirmación se sustenta } \\
\text { en un evento, el cual es } \\
\text { utilizado como prueba. }\end{array}$ & $\begin{array}{l}\text { Q es respaldado } \\
\text { por } P\end{array}$ & $\begin{array}{l}\text { El determinar a quién le corresponde } \\
\text { probar un hecho tiene enorme interés, } \\
\text { pues hay muchas situaciones en la } \\
\text { vida de las relaciones jurídicas en } \\
\text { que el éxito o el fracaso del resultado } \\
\text { del proceso va a depender de la } \\
\text { prueba de un hecho. }\end{array}$ \\
\hline $\begin{array}{l}\text { Deducción- } \\
\text { evidencia }\end{array}$ & $\begin{array}{l}\text { Relación que se } \\
\text { establece cuando una } \\
\text { inferencia es generada } \\
\text { a partir de un(os) } \\
\text { evento(s). }\end{array}$ & \begin{tabular}{|l} 
E \\
razonamiento \\
Q es motivado \\
por P
\end{tabular} & $\begin{array}{l}\text { Este régimen de bienes, dentro de } \\
\text { nuestro actual derecho, depende de } \\
\text { la voluntad de los cónyuges, en el } \\
\text { sentido de que ellos son libres de } \\
\text { elegir el que mejor les convenga, } \\
\text { dentro, de las posibilidades de } \\
\text { elección que les ofrece la ley. } \\
\text { Existe pues una libertad restringida } \\
\text { del sistema de bienes dentro del } \\
\text { matrimonio. }\end{array}$ \\
\hline $\begin{array}{l}\text { Condición- } \\
\text { acción }\end{array}$ & $\begin{array}{lll}\text { Relación } & \text { que } & \text { se } \\
\text { establece } & \text { cuando } & \text { la } \\
\text { posibilidad de que uno } \\
\text { o más } & \text { eventos } & \text { (no) } \\
\text { ocurran } & \text { motiva } & \text { una } \\
\text { acción. } & & \end{array}$ & $\begin{array}{l}\text { Si P, se decide } \\
\text { hacer Q. }\end{array}$ & $\begin{array}{l}\text { Si no se dan todas las partes del } \\
\text { proceso de manera completa, } \\
\text { llevaremos a cabo nuestro plan de } \\
\text { emergencia. }\end{array}$ \\
\hline
\end{tabular}

Tabla 4: Descripción de las relaciones aditivas

\begin{tabular}{|l|l|l|l|}
\hline \multicolumn{4}{|c|}{ RELACIONES DE ELABORACIÓN } \\
\hline \multicolumn{1}{|c|}{ Nombre } & \multicolumn{1}{|c|}{ Definición } & Formalización & \multicolumn{1}{c|}{ Ejemplo } \\
\hline $\begin{array}{l}\text { Definición de } \\
\text { concepto }\end{array}$ & $\begin{array}{l}\text { Relación que se } \\
\text { establece cuando } \\
\text { un evento define } \\
\text { el significado } \\
\text { de un concepto } \\
\text { presente en otro. }\end{array}$ & $\begin{array}{l}\mathrm{E}_{2} \text { define } \mathrm{C} \\
\mathrm{E}_{1}\end{array}$ & $\begin{array}{l}\text { Yo pregunto, señores, qqué son } \\
\text { los gremios? Son reuniones de } \\
\text { hombres alrededor de factores } \\
\text { económicos que interesan a los } \\
\text { asociados. }\end{array}$ \\
\hline
\end{tabular}




\begin{tabular}{|c|c|c|c|}
\hline $\begin{array}{l}\text { Ejemplificación } \\
\text { de concepto }\end{array}$ & $\begin{array}{l}\text { Relación que } \\
\text { se establece } \\
\text { cuando un evento } \\
\text { ejemplifica un } \\
\text { concepto presente } \\
\text { en otro. }\end{array}$ & $\begin{array}{l}\mathrm{E}_{2} \text { ejemplifica } \mathrm{C} \\
\text { en } \mathrm{E}_{1}\end{array}$ & $\begin{array}{l}\text { Conocemos numerosos sistemas } \\
\text { en los que sobresale en primer } \\
\text { término la organización en el } \\
\text { tiempo. En calidad de ejemplo } \\
\text { de esos sistemas puede servirnos } \\
\text { cualquier obra musical, una } \\
\text { sinfonía, pongamos por caso. }\end{array}$ \\
\hline $\begin{array}{l}\text { Especificación } \\
\text { de concepto }\end{array}$ & $\begin{array}{l}\text { Relación que } \\
\text { se establece } \\
\text { cuando un evento } \\
\text { especifica un } \\
\text { concepto presente } \\
\text { en otro. }\end{array}$ & $\begin{array}{l}\mathrm{E}_{2} \text { especifica } \mathrm{C} \\
\text { en } \mathrm{E}_{1}\end{array}$ & $\begin{array}{l}\text { Se suele situar a los meteoritos en } \\
\text { dos grupos principales: meteoritos } \\
\text { de hierro (metálicos) y meteoritos } \\
\text { de piedra. Los primeros están } \\
\text { formados esencialmente por } \\
\text { hierro, níquel y cobalto. Los } \\
\text { meteoritos de piedra contienen una } \\
\text { cantidad bastante menor de hierro. }\end{array}$ \\
\hline $\begin{array}{l}\text { Reformulación } \\
\text { de concepto }\end{array}$ & $\begin{array}{l}\text { Relación que } \\
\text { se establece } \\
\text { cuando un evento } \\
\text { reformula re el } \\
\text { significado de un } \\
\text { concepto presente } \\
\text { en otro. }\end{array}$ & $\begin{array}{l}\mathrm{E}_{2} \text { parafrasea } \mathrm{C} \\
\text { en } \mathrm{E}_{1}\end{array}$ & $\begin{array}{l}\text { En este tipo de conflictos se } \\
\text { emplea la vía del apremio, es decir, } \\
\text { autorizar medios compulsivos } \\
\text { como el embargo y remate de } \\
\text { bienes del deudor para obtener el } \\
\text { cumplimiento de obligaciones. }\end{array}$ \\
\hline $\begin{array}{l}\text { Comparación de } \\
\text { conceptos }\end{array}$ & $\begin{array}{l}\text { Relación que se } \\
\text { establece cuando } \\
\text { se compara un } \\
\text { concepto presente } \\
\text { en un evento } \\
\text { con un concepto } \\
\text { presente en otro. }\end{array}$ & $\begin{array}{l}\mathrm{C} \text { en } \mathrm{E}_{1} \text { se } \\
\text { compara con } \mathrm{C} \\
\text { en } \mathrm{E}_{2}\end{array}$ & $\begin{array}{l}\text { En el varón la espermatogénesis } \\
\text { es un proceso continuo a partir } \\
\text { de la pubertad, mientras que en la } \\
\text { mujer la ovogénesis es un proceso } \\
\text { cíclico. }\end{array}$ \\
\hline $\begin{array}{l}\text { Descripción de } \\
\text { concepto }\end{array}$ & $\begin{array}{l}\text { Relación que } \\
\text { se establece } \\
\text { cuando un evento } \\
\text { describe un } \\
\text { concepto presente } \\
\text { en otro. }\end{array}$ & $\begin{array}{l}\mathrm{E}_{2} \text { describe } \mathrm{C} \\
\text { en } \mathrm{E}_{1}\end{array}$ & $\begin{array}{l}\text { En } 1758 \text { Juan Nicolás de Aguirre, } \\
\text { marqués de Montepío, fundó la } \\
\text { Casa de Huérfanos en un terreno } \\
\text { de su propiedad, donde alzó a } \\
\text { su costa los edificios necesarios. } \\
\text { Tenía esta casa la misión de } \\
\text { recibir inválidos, niños expósitos y } \\
\text { mujeres arrepentidas. }\end{array}$ \\
\hline \multicolumn{4}{|c|}{ RELACIONES DE EXTENSIÓN } \\
\hline Nombre & Definición & Formalización & Ejemplo \\
\hline Ejemplificación & $\begin{array}{l}\text { Relación que } \\
\text { se establece } \\
\text { cuando un evento } \\
\text { ejemplifica a otro. }\end{array}$ & $\begin{array}{l}E_{2} \text { ejemplifica } \\
E_{1}\end{array}$ & $\begin{array}{l}\text { La base heterogénea del respaldo } \\
\text { se debió en parte a la fuerte } \\
\text { adhesión de los electores por } \\
\text { razones personalistas y de clientela } \\
\text { política. La derecha, por ejemplo, } \\
\text { seguía teniendo importante apoyo } \\
\text { entre los campesinos y personas en } \\
\text { ocupaciones de servicio, sobre la } \\
\text { base de dichos lazos tradicionales. }\end{array}$ \\
\hline
\end{tabular}




\begin{tabular}{|c|c|c|c|}
\hline Reformulación & $\begin{array}{l}\text { Relación que se } \\
\text { establece cuando } \\
\text { un evento } \\
\text { reformula a otro. }\end{array}$ & $E_{2}$ parafrasea $E_{1}$ & $\begin{array}{l}\text { Las ciencias naturales debían } \\
\text { explicar el paso de la materia } \\
\text { inanimada a la vida, es decir, } \\
\text { debían clarificar la transmutación } \\
\text { de la materia y el origen de la } \\
\text { vida. }\end{array}$ \\
\hline Especificación & $\begin{array}{l}\text { Relación que se } \\
\text { establece cuando } \\
\text { un evento } \\
\text { especifica otro. }\end{array}$ & $E_{2}$ especifica $E_{1}$ & $\begin{array}{l}\text { Desde entonces, la incidencia } \\
\text { de Oparin ha sido muy diversa: } \\
\text { estableció el puente entre lo } \\
\text { vivo y lo inerte, redondeó la } \\
\text { teoría propuesta por Darwin con } \\
\text { respecto a la evolución, puso } \\
\text { al mundo científico a pensar } \\
\text { sobre las relaciones entre los } \\
\text { organismos y el medio que los } \\
\text { rodea, y abrió la posibilidad de } \\
\text { estudiar los fenómenos biológicos } \\
\text { en el cosmos. }\end{array}$ \\
\hline Comparación & $\begin{array}{l}\text { Relación que se } \\
\text { establece cuando } \\
\text { un evento se } \\
\text { compara con } \\
\text { otro. }\end{array}$ & $\begin{array}{l}\mathrm{E}_{2} \text { se compara } \\
\text { con } \mathrm{E}_{1}\end{array}$ & $\begin{array}{l}\text { Si unimos de cualquier modo los } \\
\text { aminoácidos para constituir la } \\
\text { cadena proteínica, no lograremos } \\
\text { nuestro propósito. Esto es lo } \\
\text { mismo que si revolvemos y } \\
\text { agitamos un montón de tipos } \\
\text { de imprenta no lograremos que } \\
\text { formen una poesía conocida. }\end{array}$ \\
\hline \multicolumn{4}{|c|}{ RELACIONES CIRCUNSTANCIALES } \\
\hline Nombre & Definición & Formalización & Ejemplo \\
\hline Temporal & $\begin{array}{l}\text { Relación que se } \\
\text { establece cuando } \\
\text { un evento } \\
\text { presenta el marco } \\
\text { temporal de la } \\
\text { acción presente } \\
\text { en otro. }\end{array}$ & $\begin{array}{l}\text { A en } E_{1} \\
\text { es situada } \\
\text { temporalmente } \\
\text { por } E_{2}\end{array}$ & $\begin{array}{l}\text { La aplicación del principio } \\
\text { evolutivo al estudio del problema } \\
\text { que nos ocupa empieza a alcanzar } \\
\text { gran desarrollo en las ciencias } \\
\text { naturales. Esto comenzó a } \\
\text { suceder en la segunda década del } \\
\text { siglo XX. }\end{array}$ \\
\hline Simultaneidad & $\begin{array}{l}\text { Relación que } \\
\text { se establece } \\
\text { cuando r un } \\
\text { evento comparte } \\
\text { el mismo marco } \\
\text { temporal que la } \\
\text { acción presente } \\
\text { en otro. }\end{array}$ & $\begin{array}{l}\text { A en } E_{1} \\
\text { mientras que } A \\
\text { en } E_{2}\end{array}$ & $\begin{array}{l}\text { Al mismo tiempo que aumentaba } \\
\text { la cantidad de sustancia } \\
\text { organizada, también se alteraba } \\
\text { constantemente la calidad de su } \\
\text { propia organización. }\end{array}$ \\
\hline
\end{tabular}




\begin{tabular}{|c|c|c|c|}
\hline Espacial & $\begin{array}{l}\text { Relación que se } \\
\text { establece cuando } \\
\text { un evento } \\
\text { presenta el marco } \\
\text { espacial de la } \\
\text { acción presente } \\
\text { en otro. }\end{array}$ & $\begin{array}{l}\text { A en } E_{1} \\
\text { es situada } \\
\text { espacialmente } \\
\text { por } E_{2}\end{array}$ & $\begin{array}{l}\text { Los problemas planteados al } \\
\text { respecto quedaron en evidencia en } \\
\text { un Consejo de Gabinete que tuvo } \\
\text { lugar el día } 28 \text { de junio de } 1932 \text { y } \\
\text { que se ocupó de la convocatoria } \\
\text { de la "Constituyente" que debía } \\
\text { dar forma definitiva al nuevo } \\
\text { régimen de gobierno socialista. } \\
\text { Según expuso allí Carlos Dávila, } \\
\text { la cuestión principal a dilucidar } \\
\text { en esta materia era si ella debía } \\
\text { tener un carácter "gremial o } \\
\text { corporativo" o si debía generarse } \\
\text { por sufragio universal. }\end{array}$ \\
\hline Modo & $\begin{array}{l}\text { Relación que se } \\
\text { establece cuando } \\
\text { un evento } \\
\text { grafica cómo se } \\
\text { desarrolla una } \\
\text { acción presente } \\
\text { en otro. }\end{array}$ & $\begin{array}{l}\mathrm{E}_{2} \text { describe } \\
\text { cómo se } \\
\text { desarrolla A } \\
\text { en } \mathrm{E}_{1}\end{array}$ & $\begin{array}{l}\text { El profesor Carrasco Delgado } \\
\text { la aborda con sentido crítico, } \\
\text { distinguiendo tiempos y lugares, } \\
\text { sin caer en un culto ucrónico y } \\
\text { utópico al texto por el texto. }\end{array}$ \\
\hline \multicolumn{4}{|c|}{ RELACIONES META DISCURSIVAS } \\
\hline Nombre & Definición & Formalización & Ejemplo \\
\hline Deícticas & $\begin{array}{l}\text { Relación que se } \\
\text { establece entre } \\
\text { dos eventos, uno } \\
\text { de los cuales } \\
\text { remite al texto. }\end{array}$ & $\begin{array}{l}\mathrm{E}_{2} \text { se vincula } \\
\text { con } \mathrm{E}_{1} \text { por } \\
\text { medio del } \\
\text { contenido de } \mathrm{T}\end{array}$ & $\begin{array}{l}\text { Como queda dicho en el capítulo } \\
\text { anterior, las sustancias orgánicas } \\
\text { más simples se forman en los } \\
\text { cuerpos celestes que nos rodean } \\
\text { sin ninguna relación con la vida. }\end{array}$ \\
\hline Valorativas & $\begin{array}{l}\text { Relación que se } \\
\text { establece entre } \\
\text { dos eventos, } \\
\text { cuando uno } \\
\text { de los cuales } \\
\text { corresponde a } \\
\text { una valoración } \\
\text { del otro. }\end{array}$ & $E_{2}$ valora $E_{1}$ & $\begin{array}{l}\text { En suma, cuando en } 1828 \text { la } \\
\text { Constitución declara que Chile } \\
\text { será una república, las principales } \\
\text { instituciones del reino, como no } \\
\text { podía ser menos, pasan a ser los } \\
\text { pilares de ella. }\end{array}$ \\
\hline
\end{tabular}

\section{MÉTOdo}

\subsection{Corpus}

El corpus de este estudio está constituido por abstracts de Artículos de Investigación Científica (AIC) de biología. Tales abstracts forman parte de las lecturas obligatorias de los estudiantes que cursan tercer y cuarto año de los programas de Licenciatura en Biología y Pedagogía en Biología y Ciencias de la Pontificia Universidad Católica de Valparaíso (Chile). Específicamente, el corpus corresponde a 80 abstracts (16.070 palabras) escritos en español, extraídos de AICs correspondientes a revistas 
especializadas nacionales e internacionales que, en su mayoría, han sido publicados durante los últimos seis años. Cada texto contiene en promedio 200 palabras.

Cabe señalar que en el proceso de construcción del corpus se realizaron entrevistas a docentes de la disciplina de biología, quienes proporcionaron información relevante para acotar los criterios de selección. Tales criterios consistieron principalmente en las líneas de estudio y las temáticas específicas que enfrentan los estudiantes de biología mientras cursan tercer y cuarto año de su carrera. De este modo, se lograba el propósito de indagar efectivamente en la configuración del abstract que circula en la disciplina.

\subsection{Enfoques de análisis}

Con el propósito de desarrollar una descripción sensible a las características discursivas del abstract de biología, utilizamos dos enfoques de análisis complementarios. En primer lugar, para llevar a cabo el análisis de las movidas retóricas, utilizamos un enfoque de análisis descendente-ascendente (Biber, Connor y Upton 2007), el que se describe de manera general en la Tabla 5. Luego, para la descripción de las relaciones de coherencia, utilizamos un enfoque descendente.

Tabla 5: Enfoque metodológico descendente-ascendente

\begin{tabular}{|c|c|}
\hline Etapas & Fases metodológicas \\
\hline DESCENDENTE & $\begin{array}{l}\text { - Revisión bibliográfica } \\
\text { - Selección de criterios }\end{array}$ \\
\hline ASCENDENTE & $\begin{array}{l}\text { - Aplicación de criterios a un microcorpus } \\
\text { - Etiquetaje de categorías } \\
\text { - Triangulación de resultados } \\
\text { - Inclusión de nuevos criterios } \\
\text { - Análisis del corpus de trabajo } \\
\text { - Integración de categorías según su naturaleza } \\
\text { - Validación con pares expertos }\end{array}$ \\
\hline
\end{tabular}

Por una parte, el enfoque metodológico descendente-ascendente se constituye por dos etapas principales (una descendente y otra ascendente), las que, a su vez, se componen de varios pasos metodológicos, a partir de los cuales pueden emerger nuevas categorías, otorgando así un marco de análisis ad-hoc al corpus de estudio. Enfoques de este tipo, opuestos a los de naturaleza descendente, permiten dar cuenta de la variación disciplinar.

Por otra parte, el análisis de las relaciones de coherencia se llevó a cabo desde un enfoque metodológico descendente (Biber, Connor y Upton 2007), es decir, a partir de la aplicación de una taxonomía preexistente. Nuestra decisión de utilizar la taxonomía de relaciones de coherencia propuesta por Ibáñez, Moncada y Santana (en prensa) se justifica pues tal marco de análisis corresponde a una taxonomía que emergió del análisis de un corpus que incluía el discurso de la biología. 


\subsection{Proceso de análisis}

\subsubsection{Análisis de las movidas retóricas}

Para dar cuenta de la organización retórica del abstract, utilizamos como marco de análisis inicial la propuesta de Hyland (2000) (ver sección 2.2.). Esta elección se debe a que dicha propuesta ha sido desarrollada exclusivamente para dar cuenta del abstract, y porque emerge a partir de un trabajo basado en corpus que contempló abstracts de diferentes disciplinas. Además, porque su plausibilidad ha sido corroborada en numerosas investigaciones.

Los abstracts fueron analizados de manera individual e independiente por cuatro analistas, proceso que involucró la lectura analítica por parte de cada uno de ellos. Luego, se compararon los análisis, alcanzando un índice de acuerdo promedio por movida de $95 \%$. Los casos donde no existía acuerdo respecto a la movida identificada fueron discutidos por los analistas hasta lograr un acuerdo. Durante la etapa ascendente del estudio, emergieron nuevas categorías de análisis, lo que nos permitió enriquecer el marco de análisis propuesto por Hyland (2000) y, de esa forma, contar con un marco de análisis ad-hoc al corpus estudiado.

A continuación presentamos un abstract extraído del corpus con la finalidad de ilustrar el proceso de análisis. Por propósitos de claridad, este abstract ha sido segmentado en sus respectivas movidas constituyentes:

$<$ INTRODUCCIÓN $>$ Desde el comienzo del siglo XIX varios muestreos y expediciones científicas nacionales e internacionales se han realizado en las islas de Pascua (IP) y Salas y Gómez (ISG). < PROPÓSITO > El objetivo de este estudio es compilar, sintetizar y analizar la información publicada sobre biodiversidad de macroalgas, macro-invertebrados y peces asociados a IP-ISG, actualizando el estado del conocimiento y haciéndolo disponible para planes de conservación. $<$ MÉTODO $>$ Se realizaron búsquedas de diferentes fuentes de información (publicaciones, expediciones, datos pesqueros, reportes técnicos, libros y bases de datos online). $<$ PRODUCTO $>$ Se han reportado 964 especies (143 especies de macroalgas, 605 de macroinvertebrados y 216 de peces), la mayoría para IP (923); para ISG se reportaron 171 especies. La riqueza de especies continúa aumentando en el tiempo, a medida que aumenta el esfuerzo de muestreo. Sin embargo, montes submarinos y fuentes hidrotermales han sido escasamente estudiados en la Zona Económica Exclusiva de Chile (ZEE). El alto porcentaje de endemismo estimado para la mayoría de los grupos taxonómicos permite identificar claramente la provincia biogeográfica Rapanuiana. El mayor nivel de endemismo lo exhiben moluscos y poríferos (33-34\%). <CONCLUSIÓN $>$ La información disponible no permite identificar diferencias entre la fauna y flora marina de IP e ISG, ni definir esfuerzos de conservación hacia objetos particulares de cada isla. No obstante, es posible sugerir que los esfuerzos de conservación deberían enfocarse en los hábitats más vulnerables aún no protegidos, ubicados hacia el límite oeste de la ZEE (fuentes hidrotermales y diversidad de tamaños de montes submarinos) (B49ab).

Como se puede observar, en este abstract se identifican diferentes movidas. Al comienzo se presenta una descripción del área en la que se circunscribe la investigación que se presentará, lo que corresponde a la movida 'introducción'. Inmediatamente, y de manera explícita, se presenta el objetivo de la investigación, lo que corresponde a la movida 'propósito'. En seguida, se proporciona información respecto a cómo se llevó a cabo el trabajo, lo que corresponde al 'método'. Luego, 
se presentan algunos de los hallazgos principales del trabajo, correspondiendo a la movida 'producto'. Finalmente, se observan algunas conclusiones generales e, incluso, sugerencias a partir de los resultados obtenidos, lo que corresponde a la movida 'conclusión'. Como se puede apreciar, en este abstract se identifican las cinco movidas constituyentes de nuestro marco de análisis inicial.

\subsubsection{Análisis de las relaciones de coherencia}

Como ya hemos venido señalando, para identificar las relaciones de coherencia utilizamos el marco de análisis de la propuesta de Ibáñez, Moncada y Santana (en prensa) (ver sección 2.3.). A continuación presentamos un fragmento extraído del corpus con el propósito de ilustrar el proceso de análisis:

Los PABs (Péptidos con Actividad Biológica) derivados del colágeno y gelatina a partir de especies marinas tienen un enorme potencial, debido a que poseen excelentes propiedades biológicas, tales como antioxidantes, antihipertensivas, anticancerígenas, antimicrobianas, neuroprotectoras, así como inducir el crecimiento de tejido óseo y retardar el envejecimiento de la piel (B29ab).

En primer lugar, identificamos que este fragmento está constituido por dos unidades, vale decir, dos eventos vinculados:

$\mathrm{E}_{1}=$ Los PABs (Péptidos con Actividad Biológica) derivados del colágeno y gelatina a partir de especies marinas podrían tener un enorme potencial,

$\mathrm{E}_{2}=$ debido a que poseen excelentes propiedades biológicas, tales como antioxidantes, antihipertensivas, anticancerígenas, antimicrobianas, neuroprotectoras, así como inducir el crecimiento de tejido óseo y retardar el envejecimiento de la piel.

En segundo lugar, determinamos qué tipo de coherencia se establece entre dichos eventos. En este caso podemos identificar que es relacional, pues entre los eventos existe una proximidad temática. Luego, aplicamos los criterios de este tipo de coherencia (ver sección 2.3.1.). En cuanto al criterio de operación básica notamos que es una relación de causalidad, dado que $\mathrm{E}_{2}$ funciona como $\mathrm{P}$ (antecedente) para dar cuenta de la situación constituyente de $\mathrm{E}_{1}$, el cual cumple el rol de $\mathrm{Q}$ (consecuente). En cuanto al criterio fuente de coherencia, observamos que la relación entre los eventos es epistémica, dado que $\mathrm{Q}\left(\mathrm{E}_{1}\right)$ es una afirmación realizada por el hablante y que se sustenta en $\mathrm{P}\left(\mathrm{E}_{2}\right)$. En cuanto a la polaridad, se aprecia que es una relación positiva, puesto que $Q\left(E_{1}\right)$ cumple la expectativa que se puede generar a partir de $P\left(E_{2}\right) y$, por último, al aplicar el criterio de orden de los eventos, identificamos que es una relación de orden no básico, dado que $\mathrm{E}_{1}$ no es el antecedente $(\mathrm{P})$ de $\mathrm{E}_{2}$, sino que es el consecuente (Q). Como ya hemos señalado previamente, a partir de la combinación de estos criterios e indicadores, emerge un tipo de relación de coherencia. En el caso del ejemplo aquí descrito, se trata de una relación deducción-evidencia. 


\section{Resultados y DiscusióN}

En esta sección presentamos los principales resultados tanto en términos de la organización retórica del abstract, como de las relaciones de coherencia que lo articulan.

\subsection{Organización retórica del abstract}

Tal como se describió en el apartado 3.1.1., para dar cuenta de las movidas y de la organización retórica prototípica del abstract de biología, el corpus fue analizado utilizando como marco de arranque la propuesta de Hyland (2000). En base a dicha propuesta, en el siguiente gráfico presentamos las movidas identificadas y su porcentaje de frecuencia:

Gráfico 1: Movidas y su frecuencia (en porcentajes)

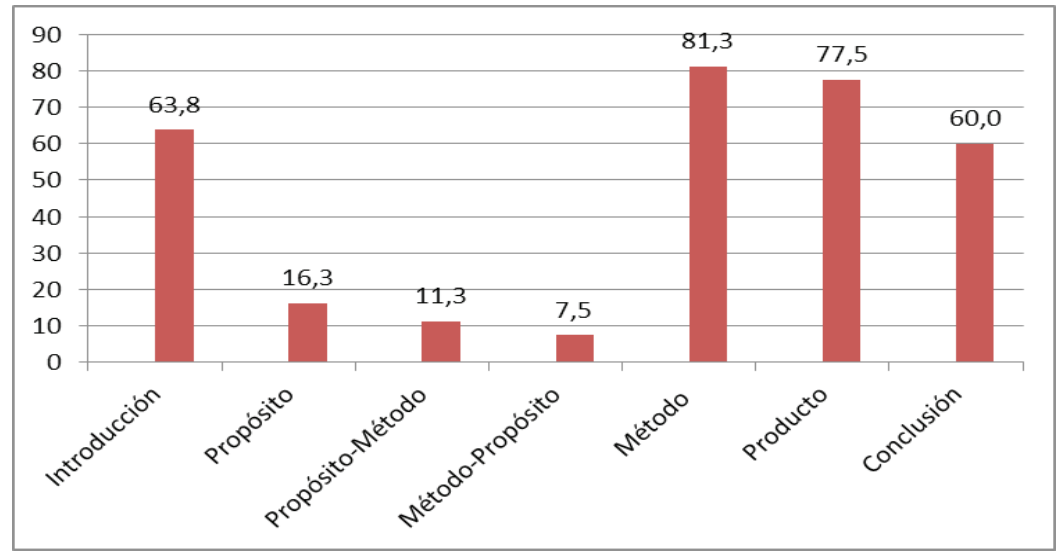

A partir del Gráfico 1 es posible observar, desde una mirada general, que en este estudio se identificaron todas las movidas constituyentes del marco inicial de análisis. Este hecho, junto con los resultados obtenidos en otros trabajos (Dos Santos 1996; Hyland, 2000; Pho 2008), nos demuestra que el abstract presenta una organización retórica relativamente estable independiente de la disciplina en la que circula. Por ello, para dar cuenta de la variación disciplinar en la organización retórica del abstract, es necesario determinar la frecuencia en la que ocurren las movidas. De este modo, y siguiendo los planteamientos de Kanoksilapatham (2005), podemos afirmar que las movidas 'introducción', 'método', 'producto' y 'conclusión' constituyen movidas obligatorias en los abstracts de biología en español, ya que superan el $60 \%$ de ocurrencia, mientras que la única movida opcional, por no superar dicho porcentaje, es 'propósito'.

Nuestros resultados sugieren que los autores de abstracts en el área de la biología no consideran prioritario explicitar el objetivo de su estudio, sino que optan por describir su investigación de manera pormenorizada y por presentar los resultados más relevantes. Esto explicaría la baja frecuencia de la movida 'propósito' (16,3\%), 
y la alta frecuencia de las movidas 'método' $(81,3 \%)$ y 'producto' $(76,3 \%)$. Esto se podría deber a que la mayoría de los abstracts analizados en nuestro trabajo, al igual que en gran parte de los estudios llevados a cabo en las ciencias exactas, dan cuenta de trabajos experimentales, un tipo de trabajo en el cual los autores proporcionan información detallada respecto del diseño de la investigación, y de cómo se llevaron a cabo los procedimientos de recolección de datos y de manipulación de las variables.

Si comparamos nuestros resultados con los obtenidos en otras investigaciones, podemos observar diferencias en cuanto a la frecuencia, lo que evidencia la variación disciplinar. Por ejemplo, en nuestro estudio, la movida 'propósito' es opcional $(16,3 \%)$, mientras que en trabajos como los de Hyland (2000) se ha corroborado que constituye una movida obligatoria en lingüística (100\%), derecho (80\%) y medicina (90\%). En cuanto a la movida más frecuente de nuestro estudio, 'método' $(81,3 \%)$, es igualmente obligatoria en lingüística y medicina (Hyland 2000), como así también en lingüística aplicada (Dos Santos 1996; Pho 2008), distinto de lo que sucede en derecho, ya que en esta disciplina se identificó sólo en el 30\% de los abstracts analizados (Hyland 2000). Estos datos nos revelan que disciplinas pertenecientes a diferentes áreas del conocimiento priorizan diferentes movidas, con el objetivo de dar a conocer los estudios mediante los cuales construyen y diseminan su conocimiento disciplinar.

Tal como hemos señalado previamente, nuestra metodología de análisis fue descendente-ascendente. Mediante esta metodología, fue posible no sólo identificar las movidas que constituyeron el marco de análisis inicial, sino que también permitió identificar dos nuevas movidas. Se trata de casos en los que se observa la combinación de dos movidas en una, tal como ilustramos a continuación con fragmentos extraídos del corpus. Para efectos de claridad, los segmentos discursivos a través de los cuales se realizan las movidas han sido individualizados con cursiva y subrayado.

11) Se evaluó el efecto insecticida de tres extractos de la planta endémica de Chile, Lepechinia chamaedryoides (Balb.) Epling (extracto polar, exudado resinoso y aceite esencial), sobre larvas del díptero Drosophila melanogaster Meigen con el fin de determinar cuál o cuáles de éstos poseen actividad biológica insecticida (BIO41).

12) Con el objetivo de establecer la relación entre la invasión de A. dealbata y la riqueza y la composición de especies en comunidades naturales del centro-sur de Chile, se registró la composición de plantas en tres condiciones de estudio: en un rodal invadido por aromo, en un bosque nativo contiguo y en el borde entre ambas condiciones (BIO45).

En el ejemplo 11) se observa que existe una combinación de las movidas 'método' (qué actividades se llevaron a cabo) y ‘propósito' (con qué finalidad se hizo). Es por ello, que esta movida fue denominada como método + propósito. Del mismo modo, el ejemplo 12) también refleja esta combinación. Sin embargo, en este caso, el orden de las movidas es diferente: primero se presenta el 'propósito' del estudio y luego se describe (parte de) la 'metodología' utilizada. Así, esta movida fue denominada como propósito + método. Ambas movidas comparten el mismo propósito comunicativo: presentar las acciones llevadas a cabo para conseguir un objetivo. Ambos casos se distinguen de las movidas 'propósito' y 'método', precisamente por el propósito comunicativo que las origina. Los ejemplos 13) y 14) dan cuenta, respectivamente, de estas movidas: 
13) Los objetivos del presente estudio son caracterizar las alteraciones branquiales desde los puntos de vista anatómico, histológico, además, determinar niveles de $\mathrm{Ca}, \mathrm{P}$ y $\mathrm{Zn}$ del tejido óseo de la columna vertebral y cráneo de salmones afectados (BIO49).

14) El bioensayo se realizó sobre la base de un diseño experimental completamente aleatorio, con 15 tratamientos y tres repeticiones, que contempló el estudio de variables de mortalidad y de concentración letal $50 \%$ (CL50) y $90 \%$ (CL90), y observación de organismos mediante lupa, microscopía óptica y microscopía electrónica de transmisión (BIO41).

En 13) se puede observar que la movida se limita a presentar el objetivo de la investigación, mientras que en 14) se proporciona información respecto de cómo se llevó a cabo el estudio, precisando la cantidad de tratamientos y de repeticiones, así como las variables estudiadas y los instrumentos empleados. Por lo anterior, se trata de movidas que cumplen el patrón prototípico y que, por lo tanto, se diferencian de las movidas ejemplificadas en 11) y 12).

En cuanto a su frecuencia, en el Gráfico 2 agregamos estas dos nuevas movidas a las presentadas en el Gráfico 1, con la finalidad de mostrar el panorama de las movidas identificadas en el corpus.

Gráfico 2: Totalidad de movidas identificadas y su frecuencia (en porcentajes)

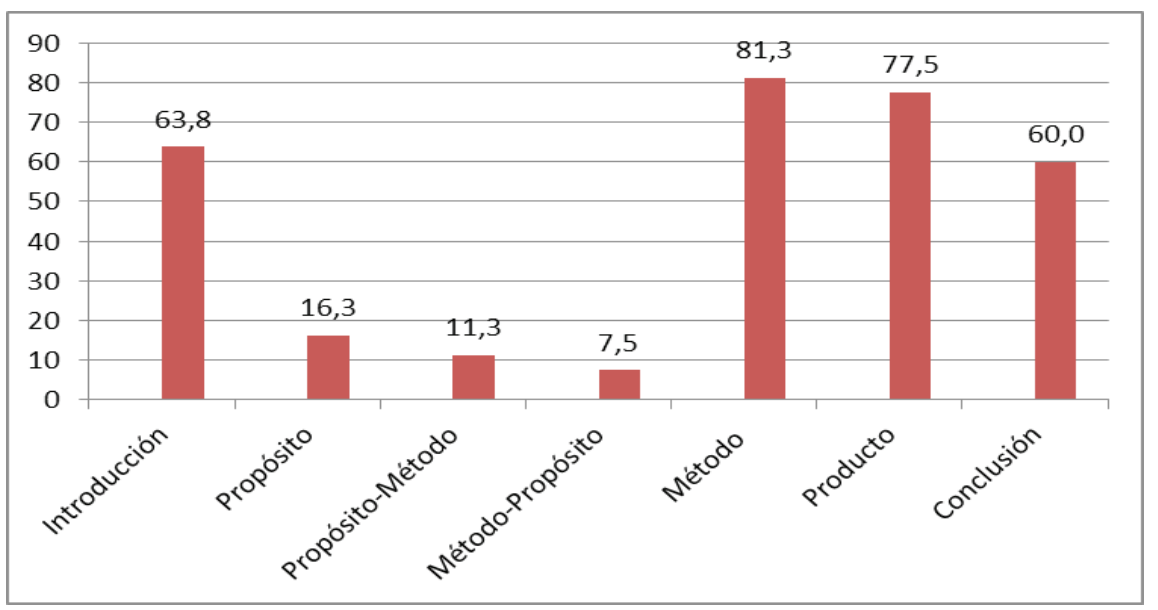

Tal como se puede apreciar en el Gráfico 2, ninguna de las dos nuevas movidas presenta altos índices de frecuencia. Sumadas, ambas no superan el $20 \%$ de ocurrencia, por lo que se trata de movidas optativas. Sin embargo, este hallazgo nos permite inferir que una de las estrategias de producción mediante la cual los autores en biología - al menos quienes escribieron los abstracts analizados en este estudiotienden a optimizar el escaso espacio con el que cuentan para dar a conocer su trabajo es la combinación de dos movidas en una. Asimismo, a partir de estas movidas podemos notar que los autores presentan el 'método' (o parte de él) de tres maneras, lo que reafirma nuestra idea de que los autores -al menos en esta disciplina-priorizan 
dar a conocer en el abstract cómo se llevó a cabo el estudio que presentan. En cuanto al 'propósito', cabe recordar que se trata de la movida con la menor frecuencia $(16,25 \%)$, incluso sumando el porcentaje de frecuencia de las dos nuevas movidas, observamos que el 'propósito' se encuentra tan sólo en el 35\% de los abstracts, por lo que se ratifica el hecho de que es una movida opcional.

Hasta este punto hemos presentado nuestros resultados en términos de los porcentajes de frecuencia de cada movida identificada. Junto con estos datos, nuestro estudio también permitió identificar los patrones con que estas movidas se presentan en el corpus. En concreto, identificamos 27 organizaciones retóricas del abstract de biología en español, tal como se muestra en el Gráfico 3:

Gráfico 3: Frecuencia de organizaciones retóricas (en porcentajes)

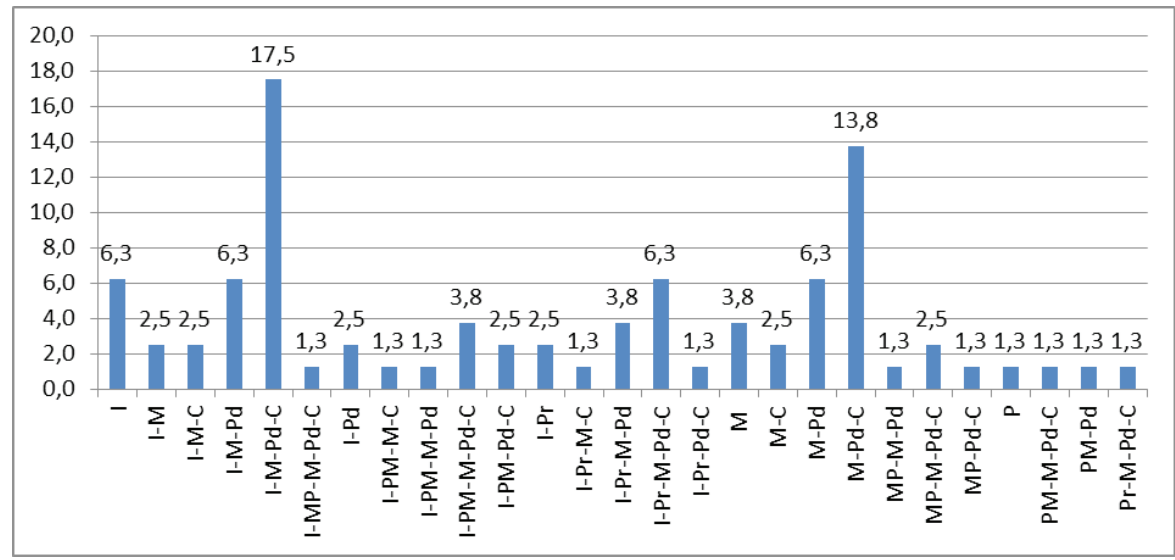

Como se puede observar en el Gráfico 3, existen numerosas organizaciones mediante las cuales se estructura el abstract de biología, muchas de las cuales se identificaron en apenas uno o dos abstracts, por lo que corresponden a configuraciones periféricas en esta disciplina. Tal es el caso de I-Pr-M-Pd o Pr-M-Pd-C, ambas con tan sólo un 1,3\% de ocurrencia. Del mismo modo, nuestros datos revelan que existen 2 organizaciones retóricas predominantes. Así, la organización retórica más frecuente, y por lo tanto, la prototípica del abstract de biología en español, es I-M-Pd-C, la que se identificó en el $17,5 \%$ de los abstracts analizados, mientras que la organización M-Pd-C corresponde a la segunda mayor frecuencia (13,8\%). Si consideramos que ambas organizaciones sólo se diferencian por la presencia de la movida 'introducción', podemos reafirmar nuestra idea de que en esta disciplina, debido a su naturaleza empírico-experimental, la configuración retórica disciplinarmente convencionalizada involucra no sólo una descripción detallada de la forma en que se llevó a cabo el estudio ('método'), sino que también la presentación de los resultados más relevantes ('producto') y de algunas proyecciones o conclusiones ('conclusión').

$\mathrm{I}=$ introducción, $\mathrm{Pr}=$ propósito, $\mathrm{PM}=$ propósito + método, $\mathrm{MP}=$ método + propósito, $\mathrm{M}$ = método, $\mathrm{C}=$ conclusión, $\mathrm{Pd}=$ producto . 
Los resultados de esta investigación son diferentes a los obtenidos en estudios focalizados en abstracts pertenecientes a otras disciplinas. Por ejemplo, Suntara y Usaha (2013) identificaron que tanto en los abstract de lingüística teórica como de lingüística aplicada la organización más frecuente es Pr-M-Pd-C, mientras que I-PrM-Pd-C e I-Pr-M-Pr representan, respectivamente, la segunda y tercera organización más frecuente. Otro aspecto interesante que emerge a partir de nuestros resultados es que muchas de las organizaciones más frecuentes involucran tres o menos movidas, como es el caso de M-Pd-C (13,8\%), I-M-Pd (6,3\%), M-Pd (6,3\%) o I (6,3\%). Estos datos refuerzan nuestra idea de que la variación disciplinar no se observa en la presencia o ausencia de ciertas movidas, sino que en la frecuencia con que se presentan entre las disciplinas, precisamente por la naturaleza de éstas y por las convenciones discursivas adoptadas para transmitir conocimiento.

\subsection{Relaciones de coherencia}

Tras la aplicación de la taxonomía, se identificaron 22 tipos de relaciones de coherencia. A continuación, presentamos detalladamente estos resultados.

\subsubsection{Relaciones de coherencia relacional identificadas en el corpus}

Como ya hemos señalado, en cuanto a la coherencia relacional, el marco de análisis adoptado distingue entre relaciones de adyacencia y de causalidad. Se identificaron 13 tipos de relaciones. La mayoría de ellas se concentró en relaciones de causalidad (11 tipos), mientras que las restantes correspondieron a relaciones de adyacencia. En la Tabla 6 se presenta la distribución de dichas relaciones:

Tabla 6: Relaciones de coherencia relacional

\begin{tabular}{|c|c|c|c|c|c|c|c|c|}
\hline \multicolumn{9}{|c|}{ COHERENCIA RELACIONAL } \\
\hline \multirow{11}{*}{ 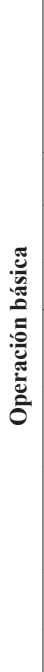 } & & \multirow{3}{*}{$\begin{array}{c}\text { Orden de los } \\
\text { eventos }\end{array}$} & \multirow{3}{*}{ Polaridad } & \multicolumn{5}{|c|}{ Fuente de coherencia } \\
\hline & & & & \multicolumn{3}{|c|}{ Contenido } & \multirow{2}{*}{$\begin{array}{l}\text { Acto de } \\
\text { habla }\end{array}$} & \multirow[t]{2}{*}{ Epistémico } \\
\hline & & & & Neutral & Volitivo & Deóntico & & \\
\hline & \multirow[t]{2}{*}{ Adyacencia } & N/A & Positivo & Conjunción & & & & \\
\hline & & N/A & Negativo & Oposición & & & & \\
\hline & \multirow[t]{6}{*}{ Causal } & Básico & Positivo & $\begin{array}{l}\text { Causa- } \\
\text { efecto }\end{array}$ & Razón-acción & & $\begin{array}{l}\text { Argumento } \\
\text { afirmación }\end{array}$ & $\begin{array}{l}\text { Evidencia- } \\
\text { deducción }\end{array}$ \\
\hline & & No básico & Positivo & $\begin{array}{l}\text { Efecto- } \\
\text { causa }\end{array}$ & Acción-razón & & $\begin{array}{l}\text { Afirmación- } \\
\text { argumento }\end{array}$ & \\
\hline & & Básico & Negativo & Contraste básico & & & & \\
\hline & & Básico & Positivo & Condición-evento & & & & \\
\hline & & Básico & Positivo & & Propósito-acto & & & \\
\hline & & No básico & Positivo & & Acto-propósito & & & \\
\hline
\end{tabular}


Como se observa en la Tabla 6, la mayoría de las relaciones de coherencia relacional identificadas en el corpus corresponden a relaciones de contenido, es decir, relaciones de naturaleza ideacional. También es posible notar que de este grupo de relaciones la mayoría se concentra en relaciones neutrales. Tal situación tiene su explicación cuando consideramos que la biología es una disciplina que alude a hechos del mundo, los que no están mediados por la voluntad, ya que, por lo general, se abordan fenómenos relacionados con la estructura de los seres vivos, sus procesos vitales y su relación con la naturaleza. Asimismo, notamos que ciertas relaciones de coherencia relacional no se identificaron en el corpus. Nos referimos a las relaciones de contenido con valor deóntico. Esto nos permitiría inferir que el discurso de esta disciplina no se caracteriza por generar relaciones que den cuenta de algún tipo de obligación, como sí sucede en derecho (Ibáñez, Moncada y Santana en prensa), por tratarse esta última de una disciplina que trata sobre normas y conductas humanas y que explicita qué se debe o no hacer dadas ciertas circunstancias.

\subsubsection{Relaciones de coherencia aditiva identificadas en el corpus}

Se identificaron 9 tipos de relaciones de coherencia aditiva. La mayoría se concentró en relaciones de elaboración. En la Tabla 7 se presenta la distribución de tales relaciones.

Tabla 7: Relaciones de coherencia aditiva

\begin{tabular}{|c|c|c|c|c|}
\hline \multicolumn{5}{|c|}{ COHERENCIA ADITIVA } \\
\hline & & \multicolumn{3}{|c|}{ TIPO DE INFORMACIÓN } \\
\hline & & Adjetival & Adverbial & $\begin{array}{c}\text { Meta } \\
\text { discursiva }\end{array}$ \\
\hline \multirow{3}{*}{ 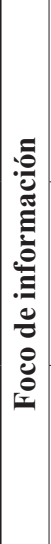 } & Concepto (C) & $\begin{array}{ll}\text { - Elaboración: } \\
\text { - } \\
\text { - } & \text { Especificación de concepto } \\
\text { - } & \text { Descripción de concepto } \\
\end{array}$ & & \\
\hline & Acción (A) & & $\begin{array}{ll}\text { - } & \text { Circunstancial: } \\
\text { - } & \text { Temporal } \\
\text { - } & \text { Simultaneidad } \\
\text { - } & \text { Modo }\end{array}$ & \\
\hline & Evento (E) & $\begin{array}{ll}\text { - } & \text { Extensión: } \\
\text { - } & \text { Especificación } \\
\text { - } & \text { Comparación } \\
\text { - } & \text { Descripción }\end{array}$ & & \\
\hline
\end{tabular}

En la Tabla 7 es posible observar que la mayoría de las relaciones de coherencia aditiva identificadas en el corpus corresponden al tipo de información adjetival, es decir, se trata de relaciones en las que se complementa información en relación con 
un concepto de un evento o en relación con un evento en su totalidad. Esto se podría deber a la naturaleza del género, más que a los rasgos impuestos por la disciplina. Lo que se pretende con el abstract es precisión y persuasión. Por lo tanto, los autores deben ser eficientes al dar cuenta de su estudio y de sus principales resultados. Para ello, complementarían información especificando, comparando, describiendo, o bien, situando al lector respecto de cuándo y cómo ocurren los eventos relacionados al trabajo.

A continuación, presentamos la frecuencia de ocurrencias de estas relaciones. Tal información nos permitirá identificar con un mayor grado de precisión los tipos de relaciones que caracterizan el abstract de biología.

\subsubsection{Ocurrencia de las relaciones de coherencia en el abstract}

Se identificaron 711 relaciones de coherencia. De esta cantidad, 17\% corresponde a relaciones de coherencia aditiva y $83 \%$ a relaciones de coherencia relacional. Como ya hemos señalado, en este último tipo distinguimos las relaciones causales y las de adyacencia. Así, del total de relaciones de coherencia relacional, 65\% corresponde a relaciones de adyacencia, y $18 \%$ a relaciones causales. En la Tabla 8 presentamos en detalle el total de relaciones identificadas por tipo de coherencia.

Tabla 8: Ocurrencia de relaciones por tipo de coherencia

\begin{tabular}{|l|l|c|c|}
\hline \multirow{2}{*}{ Tipos de relación } & \multicolumn{1}{|c|}{ Casos identificados } & \multicolumn{2}{c|}{$\begin{array}{c}\text { Porcentajes de } \\
\text { representatividad en el corpus }\end{array}$} \\
\hline \multirow{2}{*}{ Coherencia relacional } & Relaciones causales & 128 & $18 \%$ \\
\cline { 2 - 4 } & Relaciones de adyacencia & 461 & $65 \%$ \\
\hline Coherencia aditiva & Relaciones aditivas & 122 & $17 \%$ \\
\hline Total de relaciones & $\mathbf{7 1 1}$ & $\mathbf{1 0 0 \%}$ \\
\hline
\end{tabular}

Desde esta mirada general, notamos que más de la mitad de las relaciones identificadas en el corpus corresponde a relaciones de adyacencia (65\%). Cabe señalar que este tipo de coherencia se concentra en dos tipos de relación: conjunción (96\%) y oposición (4\%). La predominancia de la conjunción se explicaría porque se trata de una relación mediante la cual se lleva a cabo la progresión temática, vinculando así el contenido conceptual del abstract en torno a un tema específico. En cuanto a las relaciones causales, de las 128 identificadas, las que se presentan con mayor frecuencia son argumento-afirmación (27\%), contraste básico (16\%) y razón-acción $(13 \%)$. Al tratarse de una relación eminentemente argumentativa, la predominancia de argumento-afirmación se justifica dada la naturaleza persuasiva del género. Finalmente, en cuanto a las 122 relaciones aditivas identificadas, las que se presentan con mayor frecuencia son especificación de concepto (43\%), descripción de concepto (19\%) y especificación (15\%). La alta frecuencia de la relación especificación de concepto se explicaría porque mediante su establecimiento es posible proporcionar información detallada acerca de los diferentes aspectos teóricos y metodológicos involucrados en la investigación. 
A partir de estos resultados de frecuencia, es posible concluir que el abstract de biología se articula principalmente en términos de relaciones de adyacencia (conjunción y oposición). En segundo lugar, predominan las relaciones causales (argumentoafirmación, contraste-básico y razón-acción). Y por último, predominan las relaciones aditivas (especificación de concepto, descripción de concepto y especificación).

\subsubsection{Ocurrencia de las relaciones de coherencia en las movidas del abstract}

Tal como señalamos previamente, identificamos 711 relaciones de coherencia, de las cuales, la gran mayoría puede ser asociada a una movida retórica en particular. Con la finalidad de obtener un mayor grado de exhaustividad en la descripción de este género, en la Tabla 9 presentamos las relaciones de coherencia más frecuentes por cada una de las movidas constituyentes de la organización retórica del abstract.

Tabla 9: Movidas retóricas del abstract y sus relaciones de coherencia más frecuentes

\begin{tabular}{|c|c|c|c|c|c|c|c|c|}
\hline \multicolumn{9}{|c|}{ Movidas retóricas identificadas } \\
\hline \multirow{5}{*}{ 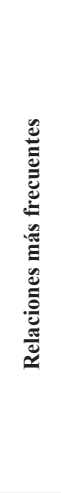 } & Introducción & Propósito & $\begin{array}{l}\text { Propósito- } \\
\text { Método }\end{array}$ & $\begin{array}{l}\text { Método- } \\
\text { Propósito }\end{array}$ & Método & Producto & Conclusión & \\
\hline & $\begin{array}{l}\text { Conjunción } \\
(40 \%)\end{array}$ & $\begin{array}{l}\text { Conjunción } \\
(60 \%)\end{array}$ & $\begin{array}{l}\text { Propósito- } \\
\text { acto } \\
(66,6 \%)\end{array}$ & $\begin{array}{l}\text { Acto- } \\
\text { propósito } \\
(100 \%)\end{array}$ & $\begin{array}{l}\text { Conjunción } \\
(68,3 \%)\end{array}$ & $\begin{array}{l}\text { Conjunción } \\
(68,9 \%)\end{array}$ & $\begin{array}{l}\text { Conjunción } \\
(53,1 \%)\end{array}$ & \\
\hline & $\begin{array}{l}\text { Especificación } \\
\text { de concepto } \\
(12,3 \%)\end{array}$ & $\begin{array}{l}\text { Razón- } \\
\text { acción } \\
(20 \%)\end{array}$ & $\begin{array}{l}\text { Modo } \\
(22,2 \%)\end{array}$ & & $\begin{array}{l}\text { Especificación } \\
\text { de concepto } \\
(11,7 \%)\end{array}$ & $\begin{array}{l}\text { Especificación } \\
\text { de concepto } \\
(5,8 \%)\end{array}$ & $\begin{array}{l}\text { Argumento- } \\
\text { afirmación } \\
(6,3 \%)\end{array}$ & \\
\hline & $\begin{array}{l}\text { Argumento- } \\
\text { afirmación } \\
(8,4 \%)\end{array}$ & $\begin{array}{l}\text { Modo } \\
(13,3 \%)\end{array}$ & & & $\begin{array}{l}\text { Acto-propósito } \\
(5,1 \%)\end{array}$ & $\begin{array}{l}\text { Oposición } \\
(5,4 \%)\end{array}$ & $\begin{array}{l}\text { Afirmación- } \\
\text { argumento } \\
(6,3 \%)\end{array}$ & \\
\hline & $\begin{array}{l}\text { Contraste } \\
\text { básico } \\
(8,4 \%)\end{array}$ & & & & & & $\begin{array}{l}\text { Contraste } \\
\text { básico } \\
(6,3 \%)\end{array}$ & \\
\hline Total & 130 & 15 & 9 & 4 & 136 & 222 & 47 & 563 \\
\hline
\end{tabular}

Con el propósito de graficar la relación entre las movidas retóricas del abstract de biología y las relaciones de coherencia que las caracterizan, presentamos las tres relaciones de coherencia más frecuentes en cada movida. Cabe señalar que en prácticamente todas las movidas del abstract la relación de coherencia más frecuente es la de conjunción. Si bien es evidente que esta alta frecuencia es congruente con los resultados generales que presentamos en el apartado 4.2.3., también es cierto que tal frecuencia no permite discriminar y, así, cumplir con nuestro propósito de caracterizar cada movida en términos de sus relaciones de coherencia prototípicas. Por ello, la relación conjunción no será considerada para caracterizar las movidas retóricas que presentamos a continuación.

Nuestros datos revelan que las movidas constituyentes del abstract de biología están articuladas por relaciones de diferente tipo, y que su alta ocurrencia en una determinada movida se debe a la proximidad entre su naturaleza y el propósito comunicativo de la movida en la que aparece. Así, por ejemplo, la alta frecuencia 
de especificación de concepto en la movida 'introducción' se explica porque ella favorece la presentación de las características de algún hecho u objeto del área de estudio, o bien, la exposición detallada de ciertos aspectos teóricos o actividades propias del ámbito:

- Estructuralmente, las MC son heptapéptidos cíclicos y funcionalmente están clasificadas dentro del grupo de las hepatotoxinas. Las MC han originado intoxicaciones a veces incluso fatales tanto en animales como en humanos (B80ab).

Asimismo, la alta frecuencia de las relaciones argumento-afirmación y contraste básico en esta movida se explica porque la primera permite la valoración de los avances logrados en el área o bien justificar un procedimiento, como en: "La resistencia de los microorganismos a los antibacterianos es un problema mundial de salud, por lo que se hace necesario la búsqueda de nuevas alternativas terapéuticas las cuales van encaminadas a las fuentes naturales", mientras que la última permite la contextualización del trabajo a través de la presentación de los estudios previos en torno a la temática, y de los vacíos investigativos aún persistentes:

- Varios estudios han revelado una variedad de mecanismos de invasión en las plantas alóctonas. Sin embargo, aún se conoce poco sobre cómo tales mecanismos y sus efectos asociados cambian a través de diferentes estados del ciclo de vida (B46ab).

En cuanto a la movida 'propósito', predomina la relación (volitiva) razón-acción. La alta frecuencia de esta relación se explica pues en esta movida se explicita el objetivo de la investigación, el que siempre es producto de una motivación, ya sea profundizar en una línea de estudios o abordar algún vacío investigativo:

- Debido a la gran importancia ecológica que poseen estos ambientes, se estudió la diversidad, abundancia y distribución de la macrofauna betónica del litoral rocoso (B20ab).

En la movida 'método', el tipo de relación más frecuente corresponde a especificación de concepto. Esto se explicaría porque en esta movida se pretende proporcionar información precisa acerca de las actividades realizadas en los procesos de recolección de datos, de los instrumentos utilizados y de las técnicas empleadas:

- Los peces fueron capturados mediante buceo apnea e inmediatamente trasladados vivos al laboratorio. Cada pez fue medido (longitud total) y pesado (peso total, eviscerado, hígado y gónadas) (B76ab).

Otra relación frecuente en esta movida es acto-propósito, lo que resulta natural dado que las actividades o los procedimientos llevados a cabo durante la investigación están orientados por un objetivo:

- Se prepararon diluciones dobles del PMA desde 5.07 a $650 \mathrm{mg} / \mathrm{ml}$ para determinar la concentración mínima inhibitoria (CMI) capaz de inhibir el crecimiento bacteriano (B47ab).

En cuanto a las movidas 'propósito-método' y ‘método-propósito', predominan las relaciones acto-propósito y propósito-acto. La alta frecuencia de estas relaciones 
volitivas se explica porque en ambas movidas se explicitan tanto el objetivo de la investigación, como las actividades llevadas a cabo para su consecución (ver ejemplos 11 y 12).

En la movida 'producto', la relación más frecuente es especificación de concepto. Esto es atribuible al hecho de que con esta relación es posible añadir información detallada acerca del comportamiento observado en los sujetos de estudio, como así también de los rasgos principales de las especies identificadas:

- Se encontraron 85 especies introducidas, pertenecientes a 21 familias y 65 géneros. Las familias mejor representadas en número de especies fueron Poaceae (22spp.), Asteraceae (11 spp.) y Caryophyllaceae (7 spp.) (B75ab).

La segunda relación más frecuente en esta movida es la de oposición. Esta frecuencia resulta lógica, pues a través de ella es posible contrastar los diferentes resultados obtenidos en el estudio o confrontarlos con los obtenidos en otros trabajos, relevando así la profundidad y la relevancia de la investigación:

- La presencia de C. solstitialis (plantas o semillas) no disminuyó la germinación de las especies nativas de Baccharis. Sin embargo, la presencia de plantas establecidas de C. solstitialis disminuyó significativamente la biomasa de las plantas de Baccharis (B46ab).

Finalmente, en la movida 'conclusión' predominan las relaciones de tipo argumentativo (argumento-afirmación, afirmación-argumento). Esto se debería a la naturaleza persuasiva del abstract, ya que en esta movida los autores pretenden persuadir respecto de la validez y la relevancia de los resultados obtenidos, y acerca de lo apropiado de los métodos utilizados:

- El alto porcentaje de supervivencia ( $>80 \%)$, el incremento de la longitud de la concha y la alta producción de tejido reproductivo, sugieren una excelente condición fisiológica de $P$. viridis, (...), por lo que el cultivo de fondo puede constituir una alternativa de producción acuícola (B10ab).

La otra relación más frecuente en esta movida es contraste básico, lo cual se explicaría porque ella permite destacar las fortalezas del trabajo, como así también algunas deficiencias, a partir de las cuales se pueden proyectar nuevas investigaciones:

- La poca información de la composición y distribución macrobentónica del litoral rocoso impide una mejor comparación, no obstante los resultados contribuyen al conocimiento de la biodiversidad en esta región (B20ab).

Tal como hemos venido exponiendo, en este estudio hemos podido determinar, a partir de su frecuencia, las relaciones de coherencia que permiten caracterizar cada una de las movidas que organizan el abstract de biología. Sin embargo, cabe consignar que se identificaron 148 relaciones que no pudieron ser asociadas a una movida en particular, por cuanto se establecen entre dos movidas diferentes. Ello explica la diferencia en los totales de relaciones presentados en las Tablas 8 y 9 .

No obstante lo anterior, consideramos relevante haber identificado que este género no sólo se articula a través de relaciones que se establecen al interior de cada 
movida, sino que también lo hace a través de relaciones que vinculan dos movidas, tal como ilustramos en el siguiente ejemplo extraído del corpus:

- 15) ( $\left.E_{1}\right)$ Respecto a los resultados de la actividad biológica del extracto purificado, éste mostró actividad antibacteriana, antifúngica y citotóxica frente a una línea celular de neuroblastoma. $\left(\mathrm{E}_{2}\right)$ Los resultados de este estudio se convierten en la primera caracterización de moléculas con actividad biológica desde Athyonidium chilensis (B56ab).

Este caso corresponde a una relación argumento-afirmación, por cuanto, a partir de los resultados obtenidos, se presenta una aseveración que releva la importancia del estudio llevado a cabo. El evento correspondiente al argumento $\left(\mathrm{E}_{1}\right)$ se encuentra en la movida 'producto', mientras que el correspondiente a la afirmación $\left(\mathrm{E}_{2}\right)$ es parte de la 'conclusión', estableciéndose así una relación entre dos movidas.

\section{Conclusiones}

A partir de los resultados obtenidos en esta investigación, hemos corroborado que la presencia de ciertos aspectos discursivos y la frecuencia con la que se manifiestan constituyen evidencia de la variación disciplinar. Esto, pues si bien nuestro estudio no fue contrastivo, los resultados obtenidos presentan patrones diferentes a los observados en trabajos similares desarrollados en otras disciplinas (Hyland 2000; Samraj 2002; Pho 2008). Así, en cuanto a la organización retórica, nuestro análisis reveló la existencia de movidas que tienen poca frecuencia en el corpus y que, por lo tanto, son opcionales, mientras que en otras investigaciones se ha constatado que se trata de una movida obligatoria para otras disciplinas, como sucede con el caso de 'propósito'. En cuanto a las relaciones de coherencia identificadas en este trabajo, y debido a que se trata de un aspecto poco explorado en el género abstract -y particularmente en español-, no contamos con antecedentes que nos permitan establecer comparaciones. Sin embargo, a partir del estudio de Ibáñez, Moncada y Santana (en prensa), es posible hipotetizar que los tipos y frecuencia de las relaciones de coherencia presenten diferencias entre disciplinas.

Un hallazgo interesante de esta investigación es la identificación de la predominancia de ciertas relaciones de coherencia en ciertas movidas. Dicha predominancia es lógica si se tiene en cuenta el propósito comunicativo de estas últimas. Así, por ejemplo, considerando que el propósito de 'método' es describir los pasos llevados a cabo durante la recolección de datos, es natural que la relación (aditiva) especificación de concepto sea la más frecuente en dicha movida. Esto, pues permite proporcionar información detallada acerca de los diferentes aspectos involucrados en el diseño de la investigación (muestras, instrumentos, técnicas de medición, etc.). Asimismo, considerando que el propósito de 'conclusión' es interpretar los resultados más allá del alcance del trabajo, la alta frecuencia de las relaciones (causales) argumento-afirmación y afirmación-argumento se debe al carácter persuasivo de éstas. Ello, porque permiten relevar la importancia del estudio y su aporte al área.

A partir de estos hallazgos, no sólo fue posible probar la factibilidad de la integración de un enfoque descendente-ascendente con uno descendente para llevar 
a cabo el análisis de los abstracts, sino que también su efectividad para dar cuenta de la variación disciplinar. Junto con ello, cabe destacar la utilidad de llevar a cabo estudios más abarcadores que no se limiten a la descripción de un solo rasgo de los géneros (Lorés 2014). De esta manera, estudios de naturaleza integradora facilitan el avance del conocimiento científico, en tanto permiten ratificar hallazgos preliminares a partir de la medición de unidades de análisis diferentes.

Por lo anteriormente expuesto, creemos que con esta investigación aportamos a los estudios del discurso académico desde una perspectiva novedosa. Al describir el abstract no sólo desde su organización retórica, sino que también desde las relaciones de coherencia que lo articulan, proporcionamos nuevos antecedentes para la caracterización de este género, lo que nos permite entender sus mecanismos subyacentes, al menos para la disciplina de biología y para el español. Por lo mismo, siguiendo el enfoque metodológico utilizado en este estudio, es posible proyectar investigaciones contrastivas no sólo en términos disciplinares, sino que también entre lenguas.

Con un fin pedagógico, y asumiendo la relevancia del desarrollo de estrategias de producción escrita en el proceso de integración disciplinar exitoso, nuestros datos representan insumos a partir de los cuales es posible llevar a cabo una intervención didáctica orientada a desarrollar estrategias de producción escrita ad hoc a las características del abstract en la disciplina, complementado así aquellas propuestas basadas en la organización retórica. Esto se justifica en el hecho de que, como se ha demostrado en numerosos estudios, cada disciplina ha convencionalizado sus propias formas de construir y transmitir su conocimiento, por lo que la producción de un abstract, o de cualquier otro género, implica el desarrollo de estrategias que sean adecuadas a cada disciplina.

\section{OBRAS CITADAS}

Albadalejo, Tomás. 1981. “Aspectos del análisis formal de textos”. Revista Española de Lingüística 11.1: 117-160.

Bazerman, Charles. 1988. Shaping written knowledge: The genre and activity of the experimental article in science. Madison: University of Wisconsin Press.

Bernárdez, Enrique. 1982. Introducción a la lingüística del texto. Madrid: Espasa-Calpe.

Bhatia, Vijay. 1993. Analyzing genre. Language use in professional settings. Harlow: Longman. 2002. "A generic view of academic discourse". En Flowerdew, John (Ed.), Academic discourse. London: Longman. 21-39. 2004. Worlds of written discourse. A genre based view. Sydney: Continuum.

Biber, Douglas, Ulla Connor y Thomas Upton (Eds.). 2007. Discourse on the move. Using corpus analysis to describe discourse structure. Amsterdam: Benjamins. , Susan Conrad y Randi Reppen. 1998. Corpus linguistics: Investigating language structure and use. Cambridge: Cambridge University Press. , et al. 1999. Longman grammar of spoken and written English. Harlow: Longman.

Bolívar, Adriana, Rebecca Beke y Martha Shiro. 2010. "Las marcas lingüísticas del posicionamiento en las disciplinas: Estructuras, voces y perspectivas discursivas". En Parodi, Giovanni (Ed.), Alfabetización académica y profesional en el siglo XXI: Leer y escribir desde las disciplinas. Santiago: Ariel-Academia Chilena de la Lengua. 95-125.

Bondi, Marina y Rosa Lorés. 2014. Abstracts in academic discourse: Variation and change. Bern: Peter Lang. 
Bunton, David. 2002. "Generic moves in Ph.D. thesis introductions". En Flowerdew, John (Ed.), Academic discourse. London: Longman. 57-75.

Charles, Maggie. 2003. ““"The mystery...”: A corpus-based study of the use of nouns to construct stance in theses from two contrasting disciplines". Journal of English for Academic Purposes 2.4: 213-326.

De Beaugrande, Robert y Wolfgang Dressler. 1981. Introduction to text linguistics. London: Longman.

Dos Santos, Mauro. 1996. "The textual organization of research paper abstracts in applied linguistics". Text \& Talk 16.4: 481-499.

Farjami, Hadi. 2013. "A corpus-based study of the lexical make-up of applied linguistics article abstracts". The Journal of Teaching Language Skills 5.2: 27-50.

Ge, Dongmei y Ruiying Yang. 2005. "A genre analysis of research article abstracts". Modern Foreign Languages 28.2: 38-46.

Gholami, Javad, Zahra Mosalli y Shiva Bidel. 2012. "Lexical complexity and discourse markers in soft and hard science articles". World Applied Sciences Journal 17.3: 368-374.

Grabe, William y Robert Kaplan. 1997. "On the writing of science and the science of writing: Hedging science text and elsewhere". En Markkanen, Raija y Hartmut Schroder (Eds.), Hedging and discourse: Approaches to the analysis of a pragmatic phenomenon in academic texts. Berlin: Walter de Gruyter. 151-167.

Halliday, Michael y Ruqaiya Hasan. 1976. Cohesion in English. London-New York: Longman. . 1988. "On the language of physical science". En Ghadessy, Mohsen (Ed.), Registers of written English: Situational factors and linguistic features. London: Pinter. 162-178.

Hyland, Ken. 1996. "Talking to the academy: Forms of hedging in science research articles". Written Communication 13.2: 251-281. .2000. Disciplinary discourse: Social interactions in academic writing. London: Longman.

2004. Disciplinary discourses. Social interactions in academic writing. Ann Arbor: University Michigan Press. y Polly Tse. 2005. "Evaluative that constructions: Signaling stance in research abstracts". Functions of Language 12.1: 39-63. y Marina Bondi. 2006. Academic discourse across disciplines. Bern: Peter Lang. .2008. "Genre and academic writing in the disciplines". Language Teaching 41.4: 543562.

2009. Academic discourse: English in a global context. London: Continuum International Publishing Group.

.2011. "Academic discourse". En Hyland, Ken y Brian Paltridge (Eds.), The continuum companion to discourse analysis. London: Continuum. 171-184.

Ibáñez, Romualdo. 2008. "Comprensión de textos académicos escritos en inglés: Relación entre nivel de logro y variables involucradas". Revista Signos 41.67: 203-229.

.2010. "El texto disciplinar en la transmisión del conocimiento especializado". Estudios Filológicos 46: 59-80.

, Fernando Moncada y Andrea Santana. (En prensa). "Variación disciplinar en el discurso académico de la biología y del derecho: Un estudio a partir de las relaciones de coherencia". Revista Onomázein.

Kanoksilapatham, Budsaba. 2005. "Rhetorical structure of biochemistry research articles". English for Specific Purposes 24.3: 269-292.

Kintsch, Walter. 1974. The representation of meaning in memory. Hillsdale: Erlbaum. . 1988. "The role of knowledge in discourse comprehension: A construction-integration model”. Psychological Review 95.2: 163-182.

Li, Yun. 2011. A genre analysis of English and Chinese research article abstracts in linguistics and chemistry. Tesis magistral inédita. San Diego: Universidad de San Diego. 
Lorés, Rosa. 2004. "On RA abstracts: From rhetorical structure to thematic organization". English for Specific Purposes 23.3: 280-302.

2008. "Authorial visibility in research article and research article abstracts: The intergeneric perspective". En Burgess, Sally y Pedro Martín-Martín (Eds.), English as an additional language in research publication and communication. Berlin: Peter Lang. $105-122$.

2014. "Lost (and gained) in translation: A contrastive (English/Spanish) analysis of rhetorical and lexicogrammatical patterns in sociology research article abstracts". En Bondi, Marina y Rosa Lorés (Eds.), Abstracts in academic discourse: Variation and change. Bern: Peter Lang. 85-110.

Mann, William y Sandra Thompson. 1988. "Rhetorical structure theory: Toward a functional theory of text organization". Text \& Talk 8.3: 243-281.

Martin, Jim. 1992. English text: System and structure. Amsterdam: Benjamins.

Martín-Martín, Pedro. 2003. "A genre analysis of English and Spanish research paper abstracts in experimental social sciences". English for Specific Purposes 22.1: 25-43.

Matthiessen, Christian. 2002. "Combining clauses into clause complexes. A multi-faceted view". En Bybee, Joan y Michael Noonan (Eds.), Complex sentences in grammar and discourse: Essays in honor of Sandra A. Thompson. Amsterdam: Benjamins. 235-320.

Melander, Bjorn, John Swales y Jim Fredrickson. 1997. "Journal abstracts from three academic fields in the United States and Sweden: National or disciplinary proclivities?". En Duszak, Anna (Ed.), Intellectual styles and cross-cultural communication. Berlin: Mouton De Gruyter. 251-272.

Nasser, Mohammed. 2013. "Genre-based analysis of Arabic research article abstracts across four disciplines". Journal of Educational and Social Research 3.3: 371-382.

Pezzini, Ornella. 2003. "Genre analysis and translation. An investigation of abstracts of research articles in two languages". Capa 2.12: 75-108.

Pho, Phuong Dzung. 2008. "Research article abstracts in applied linguistics and educational technology: A study of linguistic realizations of rhetorical structure and authorial stance". Discourse Studies 10.2: 231-250.

Redeker, Gisela. 2000. "Coherence and structure in text and discourse". En Black, William y Harry Bunt (Eds.), Abduction, belief and context in dialogue. Studies in computational pragmatics. Amsterdam: Benjamins. 233-263.

Renkema, Jan. 2009. The texture of discourse. Benjamins: Amsterdam.

Saeeaw, Supachai y Supong Tangkiengsirisin. 2014. "Rhetorical variation across research article abstracts in environmental science and applied linguistics". English Language Teaching 7.8: 81-93.

Salager-Meyer, Françoise. 1990. "Discoursal flaws in medical English abstracts: A genre analysis per research and text type". Text \& Talk 10.4: 365-384.

1992. "A text-type and move analysis study of verb tense and modality distribution in medical English abstracts". English for Specific Purposes 11.2: 93-113.

1994. "Hedges and textual communicative function in medical English written discourse". English for Specific Purposes 13.2: 149-170.

Samraj, Betty. 2002. "Disciplinary variation in abstracts: The case of wildlife behavior and conservation biology". En Flowerdew, John (Ed.), Academic discourse. London: Pearson. 40-56.

2005. "An exploration of a genre set: Research article abstracts and introductions in two disciplines". English for Specific Purposes 24.2: 141-156.

2008. "A discourse analysis of master's theses across disciplines with a focus on introductions". Journal of English for Specific Purposes 7.1: 55-67.

Sanders, Ted, Wilbert Spooren y Leo Noordman. 1992. "Toward a taxonomy of coherence relations". Discourse Processes 15.1: 1-35. 
1993. "Coherence relations in a cognitive theory of discourse representation". Cognitive Linguistics 4.2: 93-133.

.2001. "Text representation as an interface between language and its users". En Sanders, Ted, Joost Schilperoord y Wilbert Spooren (Eds.), Text representation: Psycholinguistic aspects. Benjamins: Amsterdam. 1-26.

Silver, Marc. 2006. Language across disciplines: Towards a critical reading of contemporary academic discourse. Florida: Brown Walker Press.

Spooren, Wilbert y Ted Sanders. 2008. "The acquisition of coherence relations: On cognitive complexity in discourse". Journal of Pragmatics 40.12: 2003-2026.

Suntara, Watinee y Siriluck Usaha. 2013. "Research article abstracts in two related disciplines: Rhetorical variation between linguistics and applied linguistics". English Language Teaching 6.2: 84-99.

Swales, John. 1990. Genre analysis. English in academic and research settings. Cambridge: Cambridge University Press.

Sweetser, Eve. 1990. From etymology to pragmatics. Cambridge: Cambridge University Press.

Taboada, Maite. 2009. "Implicit and explicit coherence relations". En Renkema, Jan (Ed.), Discourse, of course. Amsterdam: Benjamins. 127-140.

y William Mann. 2006. "Rhetorical structure theory: Looking back and moving ahead". Discourse Studies 8.3: 423-459.

Tseng, Fan-ping. 2011. "Analysis of move structure and verb tense of research article abstracts in applied linguistics journals". International Journal of English Linguistics 1.2: 27-39.

Van Dijk, Teun. 1977. Text and context. London: Longman. . 1980. Estructuras y funciones. Una introducción interdisciplinaria a la lingüística del texto y a los estudios del discurso. Madrid: Siglo XXI.

Varantola, Krista. 1984. On noun phrase structures in engineering English. Turku: Turun Yliopisto.

Ventola, Eija. 1994. "Abstracts as an object of linguistic study”. En Čmejrková, Světla, František Daneš y Eva Havlová (Eds.), Writing vs. speaking: Language, text, discourse, communication. Tübingen: Gunter Narr. 333-352.

Zwaan, Rolf y Gabriel Radvansky. 1998. "Situation models in language comprehension and memory". Psychological Bulletin 123.2: 162-185. 